Int. J. Dev. Biol. 55: 535-546

doi: $10.1387 / \mathrm{ijdb} .103229 \mathrm{jm}$

\title{
Tumor blood vessel visualization
}

\author{
JEANNINE MISSBACH-GUENTNER ${ }^{* 1,2}$, JULIA HUNIA ${ }^{2}$ and FRAUKE ALVES ${ }^{2,3}$ \\ ${ }^{1}$ Department of Diagnostic Radiology, University Medical Center, ${ }^{2}$ Department of Hematology and Oncology, \\ University Medical Center and ${ }^{3}$ Max-Planck-Institute of Experimental Medicine, Göttingen, Germany
}

\begin{abstract}
Significant advances have been made in understanding the role of tumor angiogenesis and its influence on tumor progression in cancer. Based on this knowledge, a series of inhibitors of angiogenesis have been developed and evaluated in preclinical and clinical trials. Since detailed information of tumor progression in response to therapy is important to assess the efficacy of antitumor treatment in vivo, noninvasive imaging techniques emerge more and more as important tools to monitor alterations in tumor growth and vessel recruitment, as well as metastatic spread over time. So far, remarkable efforts have been made to improve the technical capability of these imaging modalities based on better resolution, as well as to implement multimodal approaches combining molecular with anatomical information. Advanced imaging techniques not only allow the detection and monitoring of tumor development, but also facilitate a broad understanding of the cellular and molecular events that propagate tumor angiogenesis, as well as those occurring in response to therapy. This review provides an overview of different imaging techniques in preclinical settings of oncological research and discusses their potential impact on clinical translation. Imaging modalities will be presented that have been implemented to address key biological issues by exploring tumor angiogenic processes and evaluating antiangiogenic therapy.
\end{abstract}

KEYWORDS: noninvasive imaging technique, angiogenesis inhibitor, tumormonitoring, antiangiogenic therapy, animalmodels

\section{Introduction}

The formation of new blood vessels out of preexisting vessels - angiogenesis - is an essential step for tumor growth and spread (Folkman, 1992) and thereby strongly influences the malignant potential of cancer (Zetter, 1998). Extensive research unraveling the mechanisms underlying tumor angiogenesis resulted in targeted antiangiogenic therapies, which includes growth factor blockers (Kim et al., 1993), direct inhibitors of endothelial cell proliferation and migration (O'Reilly et al., 1997; Griffioen et al., 2001), agents disrupting tumor vessels (Tozer et al., 2005) or thrombosis inducing treatments (Nilsson et al., 2001).

However, potential adverse effects caused by antiangiogenic therapies like hypertension, thrombosis, complications of wound healing and hemorrhage require special diligence in preclinical studies and even more in clinical trials in order to assess individual risk stratification (Zakarija and Soff, 2005; Giles et al., 2006; Izzedine et al., 2007, Eremina et al., 2008; Stone et al., 2010). To monitor not only treatment response but also side effects of therapy in frequent and short intervals, imaging modalities that are noninvasive, conclusive, well tolerable and therefore arbitrary often repeatable are in high demand. Furthermore, there is a need to unravel cellular and molecular events that result from therapeutic intervention and that trigger and propagate tumor angiogenesis with its typical features like abnormal endothelial stratification, altered basement membranes, arteriovenous shunts, and blind ends (Vaupel et al., 1989).

Imaging techniques like contrast-enhanced ultrasound, nearinfrared fluorescence (NIRF) imaging, or in vivo microscopy have been improved constantly to fulfill the requirements of repeatable and thereby well tolerable tools to monitor biological processes and molecular events during tumor progression. However, these imaging devices are still mainly used experimentally in preclinical approaches. Other imaging techniques like computed tomography (CT), positron emission tomography (PET), single photon emission computed tomography (SPECT), and magnetic resonance imaging (MRI) already found their way into clinical practice. All of them provide information for diagnosis, prognosis and response

\footnotetext{
Abbreviations used in this paper: BLI, bioluminescence imaging; CT, computed tomography; FMT, fluorescence-mediated tomography; fpVCT, flat-panel based volume CT; MRI, magnetic resonance imaging; NIRF, near infrared fluorescence; PET, positron emission tomography; SPECT, single photon emission computed tomography; VEGF, vascular endothelial growth factor.
}

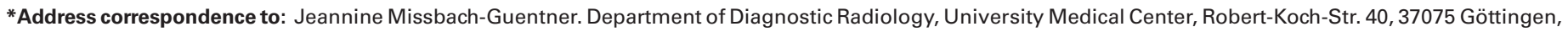
Germany. Fax: ++49 (0)551-39-8587. Tel: ++49 (0)551-39-6991. e-mail: j.missbach@med.uni-goettingen.de
}

Final, author-corrected PDF published online: 27 July 2011

ISSN: Online 1696-3547, Print 0214-6282 
to therapy in clinical oncology.

This review presents different imaging techniques that are currently used to visualize angiogenic processes in tumors focusing on preclinical application. Especially, it will give insights into new developments of imaging devices that are used in animal models towards detection of molecular alterations underlying the pathogenesis of tumor angiogenesis.

\section{Ultrasound}

Among all common noninvasive real-time imaging modalities ultrasound offers an easy to use, cost effective and portable technique with good resolution and remarkable tissue contrast in superficial structures. A key benefit is the lack of ionizing radiation which allows repeated scans in vivo and minimal burden for the laboratory animal (Lindner, 2004). Modern high frequency ultrasound devices are not longer restricted to two dimensional (2D) analysis and enable the generation of three dimensional (3D) data sets to estimate the spatial distribution of blood vessels. Clinically used Doppler ultrasound facilitates the detection of blood flow or more precisely its velocity for monitoring and staging of various types of cancer (Sedelaar et al., 2001; Yang et al., 2002; Alcàzar, 2006). Results from preclinical studies demonstrate a great benefit in signal enhancement by combining Doppler sonography with specifically modified contrast agents, so-called microbubbles. They are echogenic gas-filled vesicles with diameters between 1 and $5 \mu \mathrm{m}$, behave hemodynamically like red blood cells and can be detected with high sensitivity (Lindner, 2004). The gas core of the microbubbles oscillates in response to an ultrasonic frequency field. In the destructive mode with pulsed waves the shell of the microbubble even cracks and the gas is emitted explosively, enhancing the ultrasound backscatter. To increase their selectivity, targeted ligands like peptides or antibodies have been conjugated to the surface of microbubbles to assess for example processes
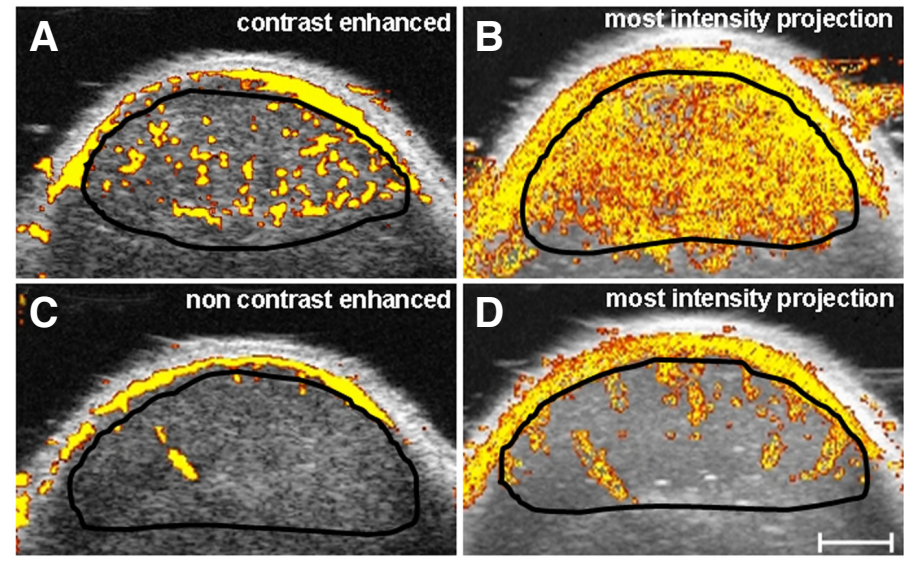

Fig. 1. Detection of tumor blood vessels by using contrast-enhanced Power Doppler ultrasound. After inoculation of human epidermoid carcinoma cells into a nude mouse, a subcutaneous tumor can be visualized in single slice images (A,B) with a thickness of $100 \mu \mathrm{m}$ and in maximum intensity projection (C,D). (A) After contrast-enhancement, small vessels become visible due to the flow-through of microbubbles, independently of flow velocities. Therefore, the capillary bed can be depicted. (B) In the noncontrast-enhanced examination the Power Doppler detects the blood flow of large tumor vessels with only high flow velocities. Bar, $1 \mathrm{~mm}$. (Image was taken with kind permission from Cancer Research (Palmowski et al., 2008)). of inflammation or angiogenesis (Klibanov, 2006; Kiessling et al., 2009). This approach has improved the properties of ultrasound up to a molecular imaging technique. It allows the in vivo characterization of tumor angiogenesis by exploring the expression of vascular biomarkers like $\alpha_{\mathrm{v} \beta 3}$-integrin and their changes during the course of disease and in response to the antiangiogenic therapy (Palmowski et al., 2009). Furthermore, the combination of native and contrast-enhanced Doppler ultrasound scans enables to differentiate between large mature vessels and small immature vessels that degrade rapidly in response to therapy. As shown in Fig. 1 Doppler ultrasound without contrast enhancement visualizes the laminar blood flow within large tumor vessels while all vessels independent of flow velocities are displayed by contrast enhancement (Palmowski et al., 2008). Design and development of new conjugates targeting key proteins related to angiogenesis like vascular epithelial growth factor receptor (VEGFR) 2 (Pillai et al., 2010) will extend the value of contrast-enhanced ultrasound in monitoring tumor vascularization in vivo in the near future.

\section{Optical imaging}

Optical imaging is based on using either bioluminescence or fluorescence as sources of contrast by detecting photons in the spectrum of visible light. Although fluorescence imaging could be an excellent tool in clinical practice to monitor tumors and processes of angiogenesis close to the surface of the lesion, so far this technique has been only well established in preclinical studies. The possibilities to noninvasively image the whole body of small rodents in longitudinal studies and to detect signals with high sensitivity in real time are distinct advantages of optical imaging techniques. The two most widely used modalities - bioluminescence imaging (BLI) and fluorescence imaging in the near infrared (NIR) range have been developed to visualize molecular processes like gene or/and protein expression or enzyme activities and metabolic changes in vivo. The feasibility of both techniques to image tumor related angiogenesis on a molecular level is demonstrated by the implementation of a variety of technical approaches, transgenic animal models and molecular probes.

\section{Bioluminescence imaging (BLI)}

Optical imaging based on BLI signals results from an enzymatic reaction in which luciferase substrates like luciferin are oxidized by means of the catalysator luciferase. This enzyme converts chemical energy into photon energy, leading to measurable emission of light (McElroy, 1951). Nowadays, the luciferase enzyme is also introduced to cancer cells by genetic engineering to visualize tumor development, growth and spread in different tumor mouse models (Jenkins et al., 2003; Rehemtulla et al., 2000), thereby restricting $\mathrm{BLI}$ to preclinical investigations. In contrast to fluorescence imaging, due to the lack of external illumination sources BLI provides very low background signals and high detection sensitivity. In addition, BLI has the advantage to detect only viable cells since only cells with metabolic activity are able to emit light in the presence of luciferin.

Transgenic mouse lines expressing luciferase have beengenerated to investigate engraftment following transplantation of stem cells (Cao et al., 2004) or in combination with tissue specific promoters that are localized upstream of the luciferase encoding gene. Genetically engineered mice with the luciferase gene under control of the vascular endothelial growth factor 2 (VEGF-2)-promoter for 
instance are perfectly suited to track endothelial cells during tumor angiogenesis by BLI (Nguyen Huu et al., 2007).

Beyond that, new elegant BLI strategies have been developed to study metabolic changes within the tumor like hypoxia (Moroz et al., 2009). Under normoxic conditions, the hypoxia inducible factor-1alpha (HIF-1 $\alpha$ ) as a key molecule for angiogenesis as well as invasion induction (Eccles, 2004) will be proteasomal degraded. However, the hypoxic situation within the tumor leads to a stabilization of the HIF-1 $\alpha$ protein. Genetically engineered tumor cell lines expressing a HIF-1 $\alpha$-luciferase fusion protein are useful reporters of the hypoxic switch: In normoxia equally to HIF-1 $\alpha$, the luciferase is degraded and no signal detection is possible. Under hypoxic conditions, luciferase is stabilized similar to HIF-1 $\alpha$ and therefore detectable by BLI (Moroz et al., 2009).

\section{Near infrared fluorescence (NIRF) imaging}

The fundamental principle of fluorescence imaging is the measurement of a fluorophore after its excitation by photons of a specific wavelength from an external light source. During relaxation to the ground state, the fluorophore emits photons at a distinct wavelength which serve as the signal for fluorescence imaging. Especially, autofluorescent effects reduce the signal to background ratio that diminish the contrast and are therefore challenging. To minimize autofluorescence and to allow observation of molecular events in deeper tissue, the use of fluorophores emitting in the NIR wavelength range between 700 to $900 \mathrm{~nm}$ is advantageous and widely used (Sevick-Muraca et al., 2002; Massoud and Gambhir, 2003).

For fluorescence imaging different fluorescent probes can be applied: I) either endogenous fluorescent proteins that exist in many colors spanning the visible spectrum from deep blue to deep red and are often genetically encoded in cells or in organisms, II) NIRF labeled ligands, peptides or antibodies that are exogenously applied to trace the fluorescence signal after binding the special target and III) activatable NIRF probes, so called "smart probes" which alter their optical properties after conformational changes, an approach to detect in particular molecular processes, for example enzyme activities of proteases (Weissleder and Pittet, 2008).

Endogenous fluorescent proteins like ubiquitously expressed GFP are reliable tools to visualize tumor growth and its progression in real time in vivo(Hoffman, 2009). To increase the informative value in murine tumor models, the host animal and the implanted tumor cells can be differently labeled. For example, transgenic mice expressing GFP exclusively in endothelial cells are suitable to study tumor-vessel-interactions by NIRF after implantation of red fluorescent protein expressing tumor cells (Yang et al., 2003).

A large quantity of articles describes the use of fluorescent labeled ligands or antibodies to monitor protein expression by NIRF imaging during steps of angiogenesis in vivo. Common targets to detect angiogenesis by NIRF imaging are angiogenic mediators like VEGF or $\alpha_{\mathrm{v} \beta 3}$-integrin. For example, the cyclic arginine-glycine-aspartic acid peptide (RGD peptide) has been widely used as probe due to its good binding properties to $\alpha_{v \beta 3}$-integrin and a high labeling efficacy, not only for NIR fluorophores such as cyanines, but also for radionuclides (Chen, 2006). VEGF receptors, known as important biomarkers for angiogenesis, are further valuable targets for NIRF imaging of angiogenesis. The single chain recombinant VEGF (scVEGF) fused to a cystein tag and labeled with Cy5.5 was shown to bind to VEGF receptors in vivo. The fusion protein accumulates at the tumor site and is internalized by receptor mediated endocytosis (Backer et al., 2007).

Since fluorescence-mediated tomography (FMT) allows exact localization of the fluorescence signals in $3 \mathrm{D}$ as well as their quantification it has been shown to be a feasible technique to study response to antiangiogenic treatment (Backer et al., 2007; Montet et al., 2007). In combination with the polymer AngioSense ${ }^{\mathrm{TM}}$ which stays within the vasculature due to its high molecular weight, both, the fluorochrome concentration in the tumor and the vascular volume fraction (VVF) of the tumor can be determined by knowing the blood concentration of the tracer. The evaluation of Bevacizumab (trade name: Avastin) on tumor neovasculature in mice with colonic tumors by FMT over time revealed a reduction of the VVF within the targeted tumor (Fig. 2) in comparison to results obtained in animals receiving only phosphate buffered saline (Montet et al., 2007).

By applying simultaneously two NIRF probes, ProSense $^{\mathrm{TM}}$, a cathepsin-
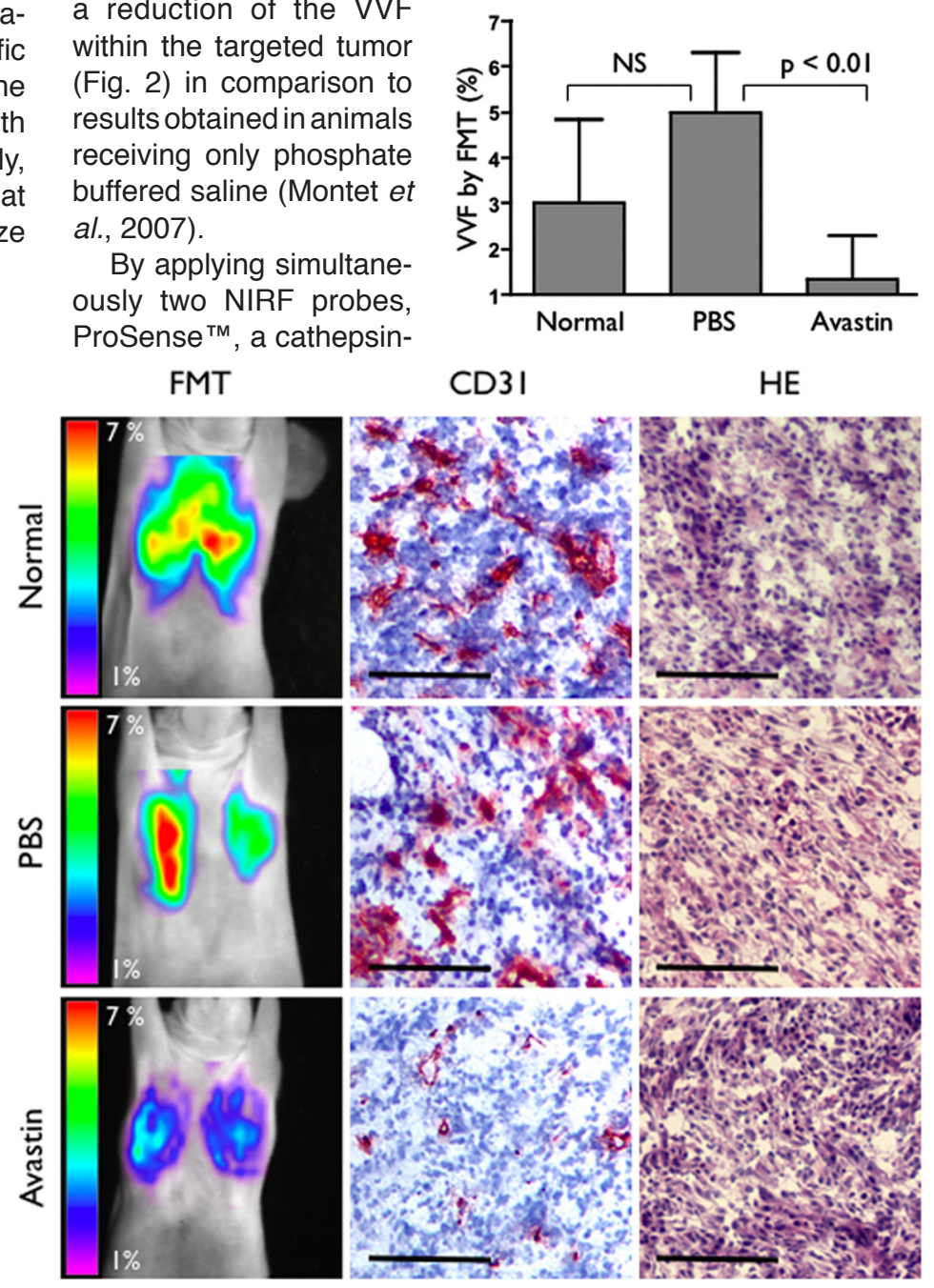

Fig. 2. Fluorescence-mediated tomography (FMT) reveals effects of Bevacizumab (Avastin) on tumor neovasculature. Nude mice bearing CT26 colonic tumors were divided in three cohorts: animals without treatment (normal), animals receiving PBS and animals treated with Bevacizumab. The reduction of the vascular vessel fraction (VVF) in the Bevacizumab group compared to both control groups as imaged by FMT was validated by imm unhostochemistry by CD31 microvascular staining and histology by hematoxylin-eosin staining. Bar, $100 \mu \mathrm{m}$. (The illustration is used with kind permission of Radiology (Montet et al., 2007)). 
activatable probe, and IntegriSense ${ }^{\mathrm{TM}}$ that targets integrins, fluorescence signals related to both fluorescent probes decreased in response to Avastin treatment corresponding to a loss of tumor volume over time in a rhabdomyosarcoma murine tumor model (Kossodo et al., 2009).

The possibility to design quenched fluorescent substrates using a quencher, which can be separated from the fluorophore after cleavage led to the generation of "smart probes" with enhanced fluorescence signal upon activation (Tsien, 2005; Mclntyre and Matrisian, 2003). This elegant approach was used first to visualize activity of matrix metalloprotease (MMP) in tumor bearing mice in response to therapy (Weissleder et al., 1999; Ntziachristos et al., 2002). MMPs are key mediators of extracellular matrix remodeling and are therefore involved in tumor-invasion and-angiogenesis.

Quenching and enhancement of a fluorescence signal depending on its surrounding offers attractive options to study not only enzyme activities but also to monitor changes of the tumor metabolism by applying $\mathrm{pH}$ - or hypoxia-sensitive activatable probes with high translational potential to the clinics.

\section{Multimodal application of BLI and NIRF imaging}

The introduction of new optical imaging systems allows the differentiation of various wavelengths to measure simultaneously luminescence- and fluorescence signals. This enables to study complex molecular processes and cell-cell-interactions during tumor angiogenesis and in response to antiangiogenic treatment. Unlike MRI or CT technologies NIRF imaging and BLI do not provide anatomical details. To overcome this drawback, the generation of fused images after multimodal scans like NIRF and flat-panel based volume CT (fpVCT) is a useful approach to co-register anatomical and molecular information (Dullin et al., 2009; Alves et al., 2009). The successful combination of MR- and optical imaging modalities was demonstrated in a preclinical approach by Hsu (Hsu et al., 2006) and his colleagues, who were pioneers in applying labeled RGD peptides to noninvasively image $\alpha_{v \beta 3}$-integrin expression in an orthotopic glioblastoma model using luciferase- (fLuc)-transgenic glioblastoma cells. BLI scans over time demonstrated increasing luminescence signal intensities due to tumor growth which correlated linearly to tumor volumes calculated from MRI scans. Further information was obtained by NIRF imaging: the fluorescent labeled RGD peptide accumulates within the tumor. This result was later confirmed by histological analysis that demonstrated the presence of the fluorescence signal specifically within tumor vasculature.

\section{In vivo microscopy}

Although many efforts were made to create realistic cell-based assays that replicate various features of the in vivo microenvironment by using several fluid or chemoattractant gradients as well as different matrix composition (Chung et al., 2010), the complex processes of angiogenesis cannot be mimicked completely by these methods. One of the advantages of in vitro assays is the accessibility of the cell culture dish to a variety of microscopic facilities. Furthermore, ex vivo microscopy investigations using particularly transgenic mouse tumor models led to outstanding knowledge in tumor angiogenesis (Bergers et al., 1998).

However, in order to shed light on vessel recruitment strategies as well as on steps of metastasis including intra- and extravasation of cells, in vivo approaches are indispensible. The combination of in vivo animal models and microscopy to investigate angiogenesis is very challenging. To access tumors developing within the organism, studies using intravital microscopy do not always fulfill the criteria of noninvasive imaging (Lin et al., 2008; Winkler et al., 2009). Easily accessible and in particular suited to be examined by in vivo microscopy of physiological vasculogenetic processes are animal models like transgenic EGFP zebrafish embryos (Hartnett et al., 2010), or the very sophisticated technique of quail/mouse chimera embryos (Pudliszewski and Pardanaud, 2005). The well established chick embryo chorioallantoic membrane model allows the testing of angiogenic as well as antiangiogenic substances (Ribatti et al., 1996).

In vivo analysis of angiogenesis by microscopy techniques in common mouse models is mostly restricted to tumors that develop subcutaneously. Here, the dorsal skin fold chamber is a well established method to repeatedly monitor tumor angiogenesis in real time with high resolution. The preparation necessitates the dissection of part of the dorsal skin flap in order to achieve a facial plane with its associated vasculature on the opposite side of the flap. Fixation of the skin by a titanium frame keeps the fold away from the body. A removable cover glass on the dissected cavity formed by the removal of the skin allows the microscopic analysis of the recruitment of blood vessels within the same tumor area over a time period of weeks (Koehl et al., 2009). The limitations of this procedure are due to the invasive and durable modulation of the skin which can induce bleeding or processes like inflammation and wound healing; both might interfere with tumor angiogenesis and thereby influence the obtained results (Koehl et al., 2009). In contrast, a noninvasive experimental approach represents the inoculation of enhanced-GFP expressing melanoma cells into the skin of the ear of mice. In this setting, growth and migration of fluorescent tumor cells can be visualized in comparison to the dark appearing blood vessels over time with confocal microscopy (Li et al., 2009).

In an orthotopic pancreatic tumor model, the microvasculature of abdominal organs in nude mice (Lin et al., 2008) was evaluated by intravital microscopy. The primary incision for tumor cell implantation was kept and used for repeated imaging of pancreatic tumors as well as organs like pancreas, liver, kidneys and colon with a fiber-optic laser scanning unit. To achieve a bright vessel contrast, the NIR fluorescent blood pool agent AngioSense $680^{\mathrm{TM}}$ was administered intravenously prior to direct scanning. This method allowed the assessment of microvessel diameter and density in the normal microvasculature as well as in malignant tissues where the tumor blood vessels were characterized by larger diameters and an altered vascular density.

Intravital microscopic imaging of cancer cells expressing genetically encoded fluorescent proteins implanted in transgenic hostmice expressing an alternative fluorescent protein is a further emerging tool in the research field of tumor angiogenesis and metastasis (Hoffman, 2009). It enables the distinction of tumor cells and host cells and therefore the visualization of their interactions. The tracking of implanted tumor cells trafficking through blood vessels or the lymphatic system of transgenic mice is an elegant method to gain information about the metastatic spread.

For example, this approach was applied to follow red fluorescent protein (RFP) - expressing glioma cells over time in an orthothopic brain tumor model of transgenic mice expressing the green fluorescent protein (GFP) protein in endothelial cells. Through a cranial 
window multiphoton microscopy was introduced to investigate microstructures of vital deep brain tissue in order to unravel mechanisms of cell dissemination and peritumoral angiogenesis. This experimental setup allowed to conclude: I) glioma cells primarily invade along the dense lattices of deep brain capillaries and II) the presence of tumor glioma cells themselves within the vasculature leads to remodeling of preexisting microvessels, including intussusceptive microvascular growth as a characteristic feature of vascular dissemination (Winkler et al., 2009).

Furthermore, multiphoton microscopy enables to depict blood vessel recruitment (Fig. 3) of distant metastases in the brain originating from breast or lung cancer (Kienast et al., 2010). As an adaptation to the needs of preclinical intravital microscopy, new,

A
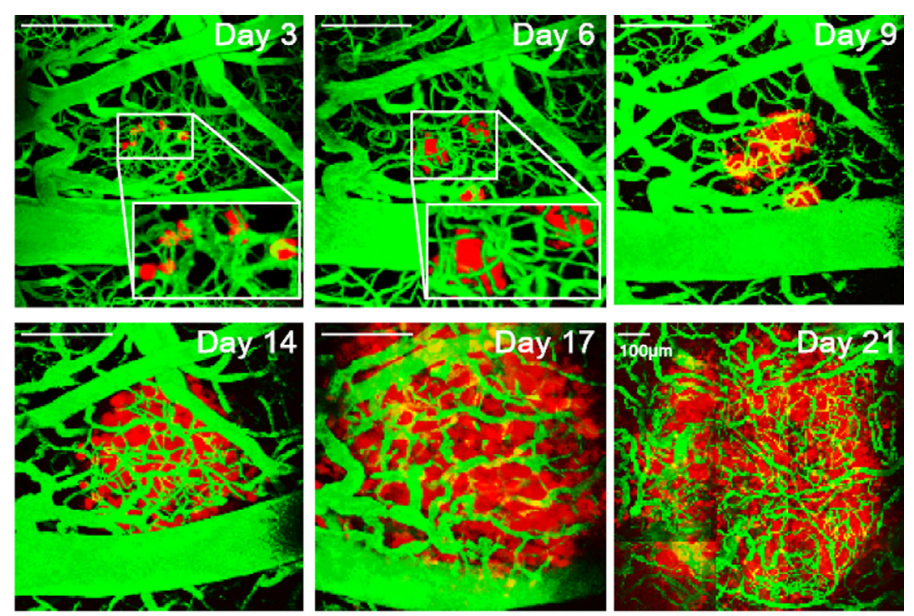

B
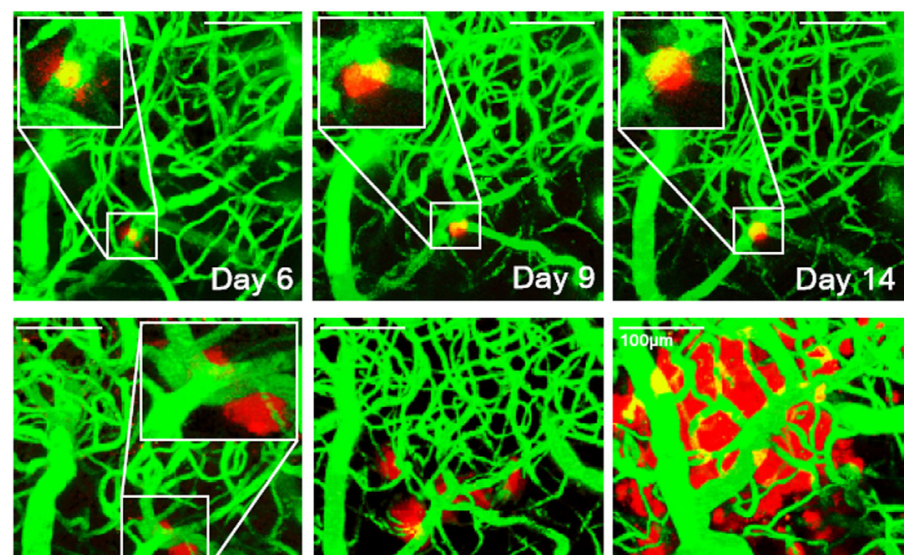

Fig. 3. Multiphoton laser scanning microscopy reveals the formation of brain metastases in real time. RFP-expressing PC14-PE6 lung cancer cells (A) and RFP-expressing MDA-MB-435 melanoma cells (B) were inoculated in nude mice after intra-arterially injection. The formation of growing macrometastases after extravasation of tumor cells and their interaction with the surrounding vasculature is obtained by FITC-dextran perfusion of the blood vessels. (A) Over a period of 21 days 5 foci of extravasated micrometastases originated from a lung tumor merge into a macrometastasis (depth: 50- $450 \mu \mathrm{m}$ ) and induces thereby massively angiogenesis. (B) In the longitudinal observation the melanoma metastasis is characterized by slow growth kinetic in comparison to $(A)$ and is located along pre-existing peritumoral blood vessels. (The illustration is reprinted by permission from Macmillan Publishers Ltd: (Nature Med) (Kienast et al., 2010)). miniaturized and portable equipment emerge this field of research to enable considerably easy handling like a $2.9 \mathrm{~g}$ two-photon laser scanning microscope which was approved for in vivo brain imaging (Piyawattanametha et al., 2009).

In the clinics, real-time microscopic approaches denote today the translation of in vivo microscopy from "bench to bedside". Confocal endomicroscopes have been aligned to elucidate in vivo malignant lesions or inflammatory processes in the gastric and colonic mucosae and in the biliary tract in patients (Smith et al., 2008).

\section{Computed tomography (CT) technologies}

X-ray-based noninvasive 3D computed tomography $(C T)$ technologies are optimal modalities to depict the skeleton structure and organs like lung in vivo by taking advantage of the constitutional contrast between air, tissue and bone (Missbach-Guentner et al., 2007). However, to visualize blood vessels surrounded by tissues of the same $\mathrm{x}$-ray absorbance, administration of contrast agent is indispensable. Here, small-molecular iodinated contrast agents are widely used for in vivo applications.

In preclinical experiments, fpVCT has been shown to offer the acquisition of a large volume with intrinsically higher spatial resolution of 150-200 $\mu \mathrm{m}$ than it is achievable with conventional CT with only slices per rotation (Kalender, 2003; Kalender and Kyriakou, 2007). FpVCT enables repeated scans in longitudinal studies and the use of isofluran anesthesia of short duration since data acquisition takes no longer than a few seconds (Kiessling et al., 2004; Greschus et al., 2005).

Regarding the assessment of tumor angiogenesis, fpVCTallows to visualize spread and loss of tumor blood vessels with excellent sensitivity. Vessels with diameters of 40 to $50 \mu \mathrm{m}$ have been detected in tumors by applying higher doses of iodine- or barium-containing contrast agents (Kiessling et al., 2004). It also enables to define morphological changes in tumor tissue over time by determination of altered uptake of contrastagents (Missbach-Guentner et al., 2008). As demonstrated in Fig. 4 the following changes could be depicted by fpVCT in an orthotopic mammary tumor SCID-mouse model, I) the recruitment of tumor vessels, II) an increase of vessel density in tumors up to 4 weeks, followed III) by a reduction of the vessels within the center of the tumor one week later. The latter finding correlated well with the appearance of a central tumor necrosis. Simultaneously, a broadening of vessel diameters was depicted due to enhanced vessel permeability and a rapid discharge of the contrast agent. By fpVCT the effect of Bevacizumab on osteolytic lesions as well as on vascularization of metastases was studied in a rat model of bone metastasis originated from breast cancer cells (Bäuerle et al., 2008). Serial fpVCT scans demonstrated not only the inhibition of bone resorption and partial or complete new bone formation in response to Bevacizumab but also alterations in angiogenesis in form of reduced branching of tumor vessels. The most challenging problem of fpVCT is its spatial resolution of 150 $\mu \mathrm{m}$ which limits the depiction of size and number of microvessels.

The capability of the CT technique in terms of resolution and therefore contrast enhancement can be improved by the use of socalled blood pool agents and the emerging micro-CT approaches which increase the spatial resolution by enhancement of doses and prolongation of scanning times. Blood pool agents possess several features concerning the pharmacodynamics and biodistribution which are advantageous in comparison to conventional 
clinically used contrast agents. Blood pool agents like the colloidal, polydisperse eXia $160^{\mathrm{TM}}$ are characterized by slow hepatobiliary excretion and long blood half life. This means, the scan has not to be accomplished immediately after administration of the blood pool agent which makes the pre-scan handling facile (Jannasch et al., 2009). In contrast, the water soluble iodinated contrast agent Isovist $300^{\mathrm{TM}}$ is excreted rapidly mainly through the kidneys and diffuses massively from the intravascular space. Hence, it is distributed within seconds between circulated blood and other extracellular fluids, leading to a loss of contrast between blood vessels and surrounding tissue during the period of scanning (Fig. 5A). Contrarily, eXia $160^{\mathrm{TM}}$ does not extravasate through the endothelium due to its large molecular weight resulting in a more detailed view of tumor vessels. This demonstrates even a more diffuse network of small vessels within the tumor in comparison to Isovist $300^{\mathrm{TM}}$ (Fig. 5B). These benefits notwithstanding, blood pool agents are only available for preclinical use at the moment (Weichert et al., 2000; Idèe et al., 2001; Kao et al., 2003).

The second approach to solve the limitation of CT technologies and to depict small blood vessels is the preclinical micro-CT. It achieves a spatial resolution of approximately 50-100 $\mu \mathrm{m}$ in vivo and up to $10 \mu \mathrm{m}$ ex vivo. However, in order to reach this excellent image resolution in vivo, high doses of radiation and long scanning times are needed (Ford et al., 2003). The limitation hereby is the continuous administration of contrast agent which is not practicable during the whole - rather long scan time.
Analogous to the in vivo studies, post mortem micro-CT also needs the administration of contrast agents. Intravenous application of barium sulfate or the lipophilic Angiofil ${ }^{\mathrm{TM}}$ is lethal and therefore only used for postmortem analysis, although, itenables outstanding contrast in depiction of microvessels (Maehara, 2008; Grabherr et al., 2008). For example, postmortem micro-CT analysis of tumor nodules within the lungs of C57/BI6 mice revealed not only the whole $3 \mathrm{D}$ vascular structure of the lung up to its microvessels but also depicted tumor microvascularization in detail. Thereby, this method allowed the evaluation of the efficacy of antiangiogenic therapy by assessing altered tumor vessel branching and immature tumor vessels (Fig. 6) in treated compared to untreated mice (Savai et al., 2009).

In the near future, the emerging micro-CT will bridge more and more the gap between the gold standard of spatial resolution as achieved by microscopic techniques and the dynamic studies of microvessel architecture in 3D.

\section{PET/SPECT imaging}

Both, positron emission tomography (PET) and single photon emission computed tomography (SPECT) provide 3D whole body images of molecular pathways in vivo with high sensitivity and specificity and have been shown to be valuable tools in the clinics since many years (Jones, 1996; Franc et al., 2008; Spanoudaki and Ziegler, 2008). PET as well as SPECT requires injection or
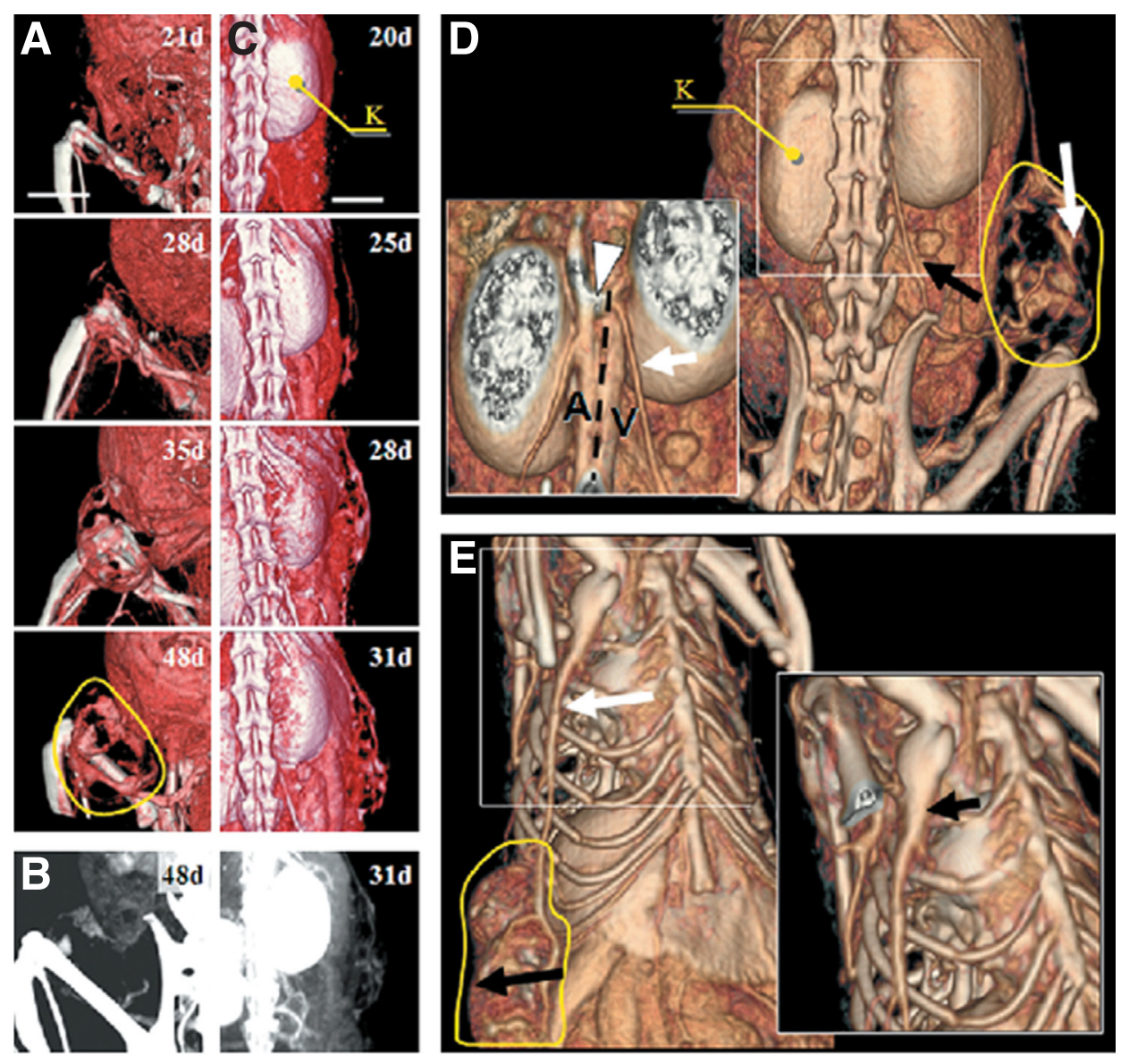

Fig. 4.3D contrast-enhanced flat-panel based volume CT ( $f p V C T$ ) data sets visualize blood vessels in severe combined immunodeficiency (SCID) mice bearing either an orthotopic mammary carcinoma or a subcutaneous mammary tumor. (A) Images of tumor vascularization over time in the orthotopic mammary tumor depict the increase of vessel number due to tumor growth until 35 days. One week later the vessel number decreases while their diameter increases. The tumor is framed. (B) In a maximum intensity projection (MIP) of the final scan (left), blood vessels within the tumor were not visible, suggesting the loss of central blood vessels and a developing central necrosis. (C) The tumor vessels of a representative subcutaneous mammary carcinoma develop permanently over a period of 31 days. One kidney is indicated (K). (B) A MIP presentation of vessel densities within the tumor indicates a homogeneous distribution of the vessel lattice infiltrating the whole tumor tissue (right). (D) Visualization of a single blood vessel (black arrow) supplying the orthotopic tumor (framed, white arrow) which can be traced to the kidneys (K). A higher magnification reveals after subtraction of the spine a connection (arrowhead) between the tumor vessel (arrow) and the upper lumbar artery. Aorta (A) and vena cava (V) are depicted as parallel running structures. (E) A large efferent vessel (white arrow) of the subcutaneous tumor (black arrow) discharges in the brachiocephalic vein (arrows) as shown in detail (right). (Image was taken with kind permission from Neoplasia (Missbach-Guentner et al., 2008)). 

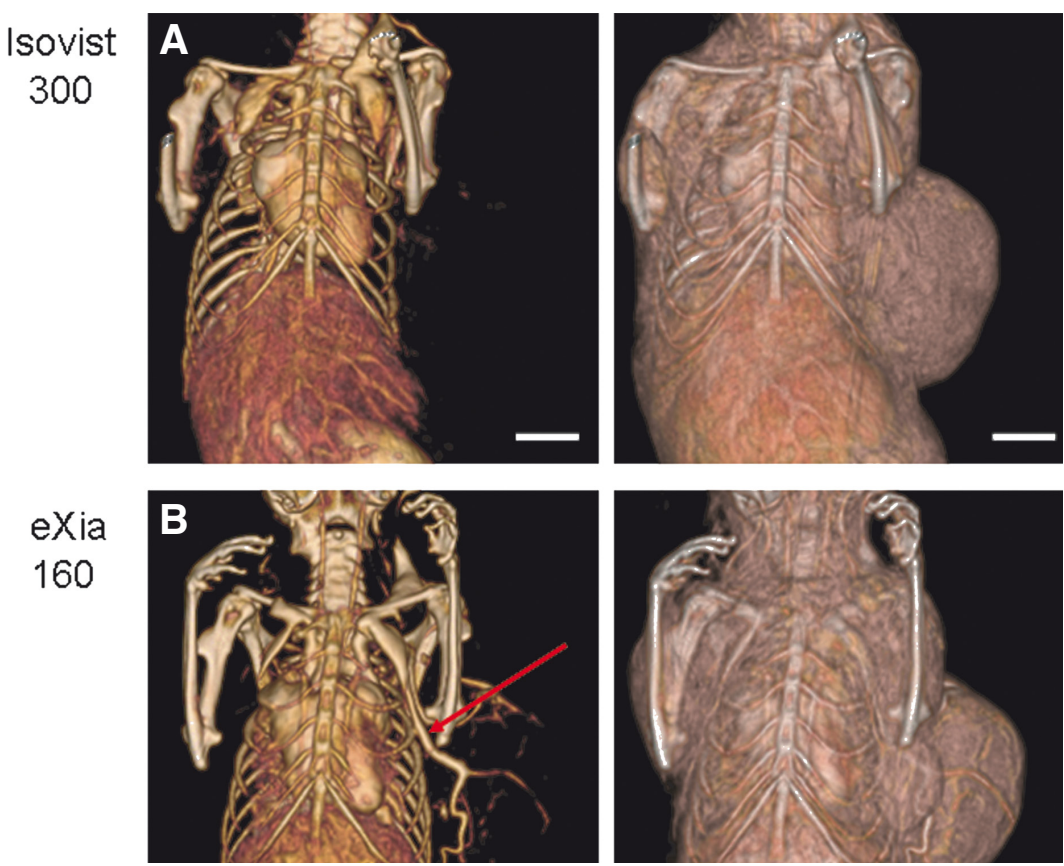

Fig. 5. Blood pool agents enhance the vessel contrast in fpVCT generated images in a mouse with spontaneous induced mammary carcinoma. (A) Two different visualization protocols of the anterior view of the tumor bearing mouse scanned with the conventional contrast agent Isovist 300. (B) Two hours later, after complete clearance of Isovist 300, a data set of the same mouse acquired after application of eXia $160^{\text {TM }}$ allows a much better depiction of small vessels at the tumor periphery. The main tumor supplying vessel discharges into the brachiocephalic vein (red arrow). Scale bars, $10 \mathrm{~mm}$. (The illustration is used with kind permission of Int. Journal of Cancer (Jannasch et al., 2009)).

inhalation of radiation-emitting radionuclides (tracer). In PET, the decay of radionuclides leads to emission of a positron which encounters an electron. The annihilation of both particles produces a pair of gamma-photons which are emitted exactly antipodal. This event can be detected by the ring shaped PET scanner. PET tracers are positron-emitting radioisotopes such as fluoride-18 (F-18) or carbon-11 (C-11) which are combined with physiologically relevant compounds. One of the major strengths of this technique is the detection of picomolar concentrations of radionuclides in body tissues that cause little or no physiological effect on the patient or laboratory animal. Furthermore, the small size of the radionuclide-compound-complex permits the monitoring of biodistribution and pharmacokinetic of probes independent of physiological consequences (Phelps, 2000).

A significant drawback of PET is the costly and tedious preparation of the radiopharmaceuticals, which normally have very short half-lives in the range of minutes, the requirements of a cyclotron and nearby radiochemistry facilities (Padhani and Neeman, 2001). To overcome these problems new radiotracers like copper-64 with longer half-lives of hours are tested for PET application with promising results (Shokeen and Anderson, 2009).

SPECT technique uses gamma emitting radioisotopes like technetium-99m with a half-life of 6 hours that is easily available at low cost. To measure the directly emitted gamma-radiation, collimators gate the bulk of rays in order to define the angle of incidence. This leads to low detection efficiency (Gambhir, 2002). Besides this disadvantage, a new design of collimators with so called pinhole apertures increase the spatial resolution of SPECT-imaging up to sub-millimeter range in contrast to PET resolution of millimeters due to the in-motion unsharpness of the emitting particles. Hence, pinhole SPECT is ideally suited for application in small animals (Goorden and Beekman, 2010). However, the emitted radiation of both techniques is measurable without limits in depth which makes PET and SPECT adequate methods for analysis of nearly all kind of tumors.

Fig. 6. Analysis of tumor vessel trees by use of micro-CT data sets in orthotopic lung tumor nodules of untreated $(A)$ in comparison to Bevacizumab-treated mice (B). The virtually segmented tumors are visualized in maximum intensity projection (MIP) versus volume rendering technique (VRT) images to provide information about vessels structure, branching angels and cross-sectional vessel area as indicated in colored circles: blue circles, $<25 \mathrm{~mm}^{2}$, green circles, 25 to $100 \mathrm{~mm}^{2}$; pink circles, 100 to $150 \mathrm{~mm}^{2}$. The occurrence of branching pattern as well as broadening of vessels in the group of treated mice confirms the antiangiogenic effect of Bevacizumab. (Image was taken with kind permission from Neoplasia (Savai et al., 2009)).
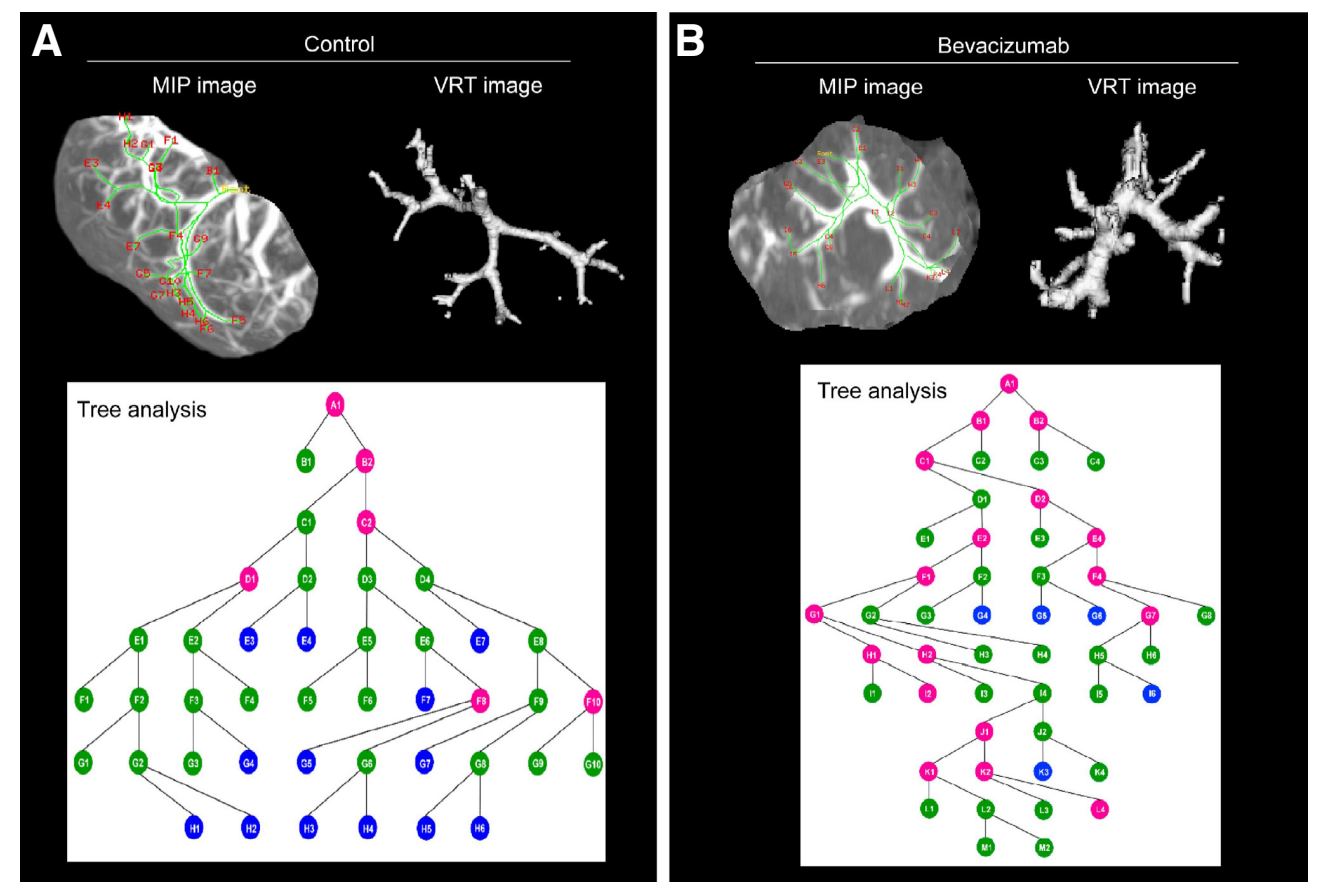
Both techniques are approved in nuclear medicine. The gold standard for detection of cancer and metastasis in patients is the use of 2-deoxy-2-[F-18]-fluoro-D-glucose as a tracer for PET imaging based on the increased metabolism found in many tumors (Wahl et al., 1991). Information that has been obtained from the visualization of angiogenesis by different PET and SPECT applications have expanded significantly in the past two decades (Wilson et al., 1992; Chen et al., 2004; Lijowski et al., 2009; Cai et al., 2009).

To identify and to quantify blood flow and tissue perfusion in tumors or to monitor response to chemotherapy later on, ${ }^{15} \mathrm{O}$-labeled water was one of the first approved radiolabeled tracers in cancer patients (Wilson et al., 1992; Tseng et al., 2004). In these studies only functional changes due to alterations of volume distribution of radiolabeled water within the tumor tissue could be determined. In current PET/SPECT approaches specific markers of angiogenesis including VEGF and its receptors, adhesion molecules like integrins serve as targets for their specific ligands conjugated with radiotracers (Chen et al., 2004; Levashova et al., 2008; Almutairi et al., 2009; Chen et al., 2009). This permits a molecular evaluation of the dynamic processes of tumor angiogenesis.

As a possibly surrogate parameter that is highly expressed in activated endothelial cells during angiogenesis (Ruoslahti, 2002), $\alpha_{v \beta 3}$-integrin served as target in a clinical study of Beer and colleagues (2007). A ${ }^{18} \mathrm{~F}$-Galacto-RGD radiotracer enabled the visualization of $\alpha_{\mathrm{v} \beta 3}$-integrin expression successfully in patients with squamous cell carcinoma of head and neck with good tumor to background ratios. The fact that ${ }^{18} \mathrm{~F}-\mathrm{FDG}$-images of the glucose metabolism were not closely related to those of $\alpha_{\mathrm{v} \beta 3}$-Integrin expression indicated an important angiogenesis specific benefit of information obtained by the use of the integrin specific radiotracer (Beer et al., 2007).

Direct radiolabeling of a Cys tag in a single chain form of VEGF with technetium $99 \mathrm{~m}$ ( ${ }^{99 \mathrm{~m} T C)}$ yields a stable and specific radiotracer for SPECT modality (Blankenberg et al., 2010). This tracer demonstrated in a preclinical setup a dramatic decrease in tumor uptake after an antiangiogenic treatment with Pazopanib which is a multi-targeted tyrosine kinase inhibitor, mainly directed against VEGFR isoforms (Fig. 7).

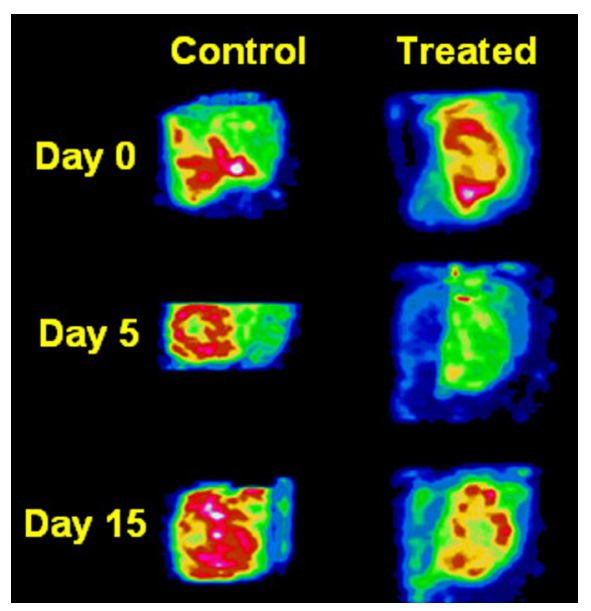

Fig. 7. Serial 3D single photon emission computed tomography (SPECT) images visualize the treatment effects of the VEGF inhibitor pazopanib in nude mice bearing subcutaneous tumor xenografts. Representative anterior oblique views of the tumors from control and treated mice demonstrate that Pazopanib significantly affects the uptake of the single chain VEGF linked to ${ }^{99 m} T$ c radiotracer in the tumor over time. At day 5 a clear reduction of the VEGF-signal is detectable. The resurgence of the signal on day 15 suggests a possible revascularization of the tumor. (The illustration is used with kind permission of Translational Oncology (Blankenberg et al., 2010)).
In order to co-register data obtained by PET and SPECT images with anatomical information, a combination of these nuclear imaging devices with CT technologies is necessary (Townsend and Beyer, 2002). Current efforts are made to develop a multimodal approach combining PET and MRI, because MR imaging provides outstanding anatomical information of especially soft tissue and an access to a variety of physiologic parameters (Catana et al., 2006).

\section{Magnetic resonance imaging (MRI)}

A highly versatile device in monitoring tumor progression is magnetic resonance imaging (MRI) since this technique provides besides a high spatial resolution an excellent contrast of opaque soft tissue. Information obtained with conventional MRI is related to the distribution of water protons within the tumor due to their magnetic characteristics. With the advantages to be noninvasive and radiation-free, MRI is one of the most widely used modalities in clinical practice. Furthermore, it is a desirable approach for assessing parameters of tumor progression like tumor growth, tumor spread and angiogenesis by determination of the vascular tumor volume in preclinical longitudinal studies.

Contrast enhancement due to administration of gadolinium (Gd)-based or iron-oxide-based magnetic contrast agents achieves excellent visualization of blood vessels particularly in combination with specific ligands targeting endothelial structures (Mulder et al., 2007; Zhang et al., 2007; Schmieder et al., 2008). Even the use of unconjugated macromolecular contrast agents with paramagnetic properties in dynamic contrast-enhanced MRI (DCE-MRI) enables to assess important features of tumor vascularization. Blood perfusion and vessel permeability for instance (Kobayashi et al., 2004) can be evaluated by measuring the diffusion of contrast agents from blood circulation out of the endothelium into the extravascular space (Ceelen et al., 2006). Combining the routinely used contrast agent Gd-diethylenetriaminepenta-acetic acid (Gd-DTPA) with an oxygen-sensitive paramagnetic agent in a hyperpolarized ${ }^{1} \mathrm{H}-\mathrm{MRI}$ permits the simultaneous visualization of microvascular permeability with tumor oxygen levels (Matsumoto et al., 2009). The possibility to correlate the vessel maturation with tissue oxygenation is of particular interest since the disorganized tumor angiogenesis results in insufficient oxygen supply as well as in a limited delivery of chemotherapeutical substances to the tumor (Jain, 2001).

One of the most important technical innovations to enhance the resolution and, in particular, the contrast of blood vessels in MR imaging, is the ultra high field (UHF) MRI. This technique improved significantly the signal-to-noise ratio, particularly in anatomical cortical vascular imaging (Burgess et al., 1999), by achieving resolutions of vessels of around $100 \mu \mathrm{m}$ in diameter (Dashner et al., 2004). In combination with ultrasmall superparamagnetic iron oxide (USPIO) blood pool contrast agents which remain intravascular for a long period of time (Weissleder et al., 1990; Tombach et al., 2004), an improved capability of data in terms of resolution can be achieved. In a study of Christoforides et al., (Christoforidis et al., 2009) not only vessels with diameters of $20 \mu \mathrm{m}$ were identified after USPIO administration in an UHF MRI approach but also the state of hypoxia within the tumor was determined. A feature of hypoxia is the accumulation of deoxyhemoglobin. Its paramagnetic effects are leading to an enhanced visualization of microvessels in absence of contrast agents (Kobayashi et al., 1980) and therefore deoxyhemoglobin can serve as a surrogate marker for hypoxia. 

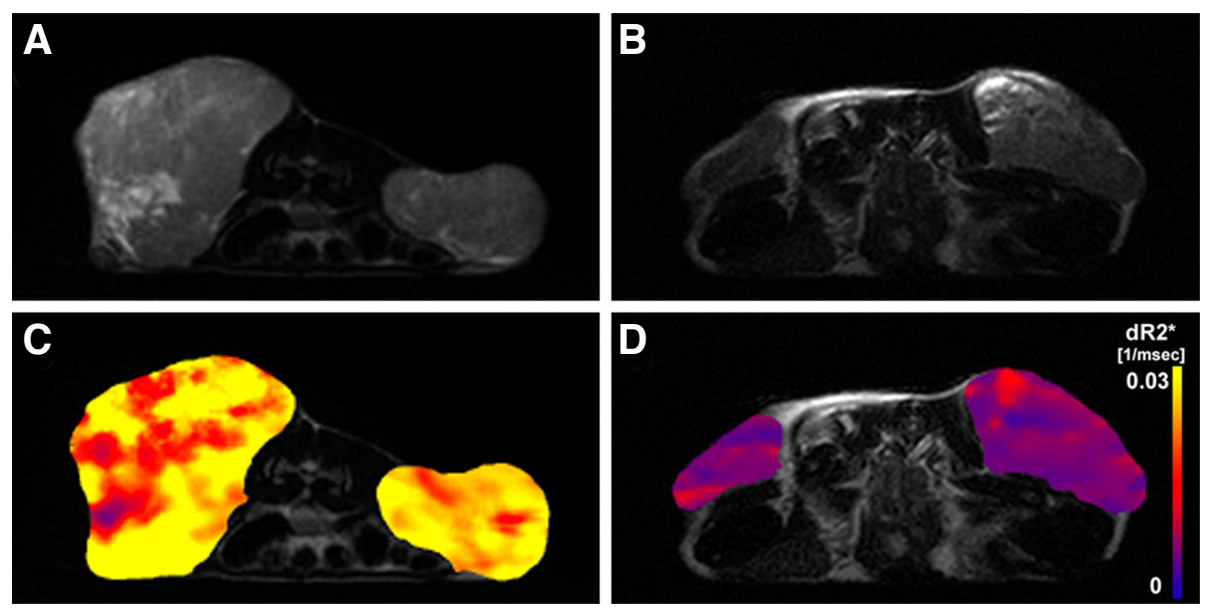

Fig. 8. Anatomic and parametric magnetic resonance (MR) images reveal the response to thrombogenic therapy after bilaterally subcutaneous implantation of fibrosarcoma cells into nude mice. $(\mathbf{A}, \mathbf{B})$ The tumors are clearly delineated shown by T2-weighted images after USPIOenhancement with high spatial resolution, 4 hours after administration of saline $(A, C)$ or trombogenic vascular targeting agent $(B, D)$. (C,D) Parametric $\Delta R 2 *$ maps which represent tumor perfusion patterns show highly vascularized tumor sections in the untreated mouse $\mathbf{( C )}$ and illustrate the response to therapy due to a decrease in tumor perfusion (D) in the treated mouse. (Image was taken with kind permission from Radiology (Persigehlet al., 2007)).
Immunohistochemical analysis supported the hypothesis that enhanced microvessel visualization correlated well with hypoxic areas within glioblastomas (Christoforidis et al., 2009). The feasibility of MRI to characterize features of tumor angiogenesis in vivo such as vessel size, vessel density, vessel size index (Troprès et al., 2004; Kiselev et al., 2005), vessel permeability, oxygen level, and hypoxic areas makes this technique highly applicable to monitor and evaluate antiangiogenic treatment.

Recently, more and more novel therapeutic agents have been evaluated in preclinical studies by MRI monitoring. For example, application of the vascular disrupting agent 5,6-dimethylxanthenoneacetic acid (DMXAA) in orthotopically implanted glioblastomas in mice showed marked extravasation and accumulation of contrast agent in the tumor in diffusion-weighted MRI, indicative for disrupted vessels (Seshadri and Ciesielski, 2009). In addition, the effect of thrombogenic vascular targeting agent (VTA) on the tumor vascularization was assessed in a murine fibrosarcoma model by MRI.
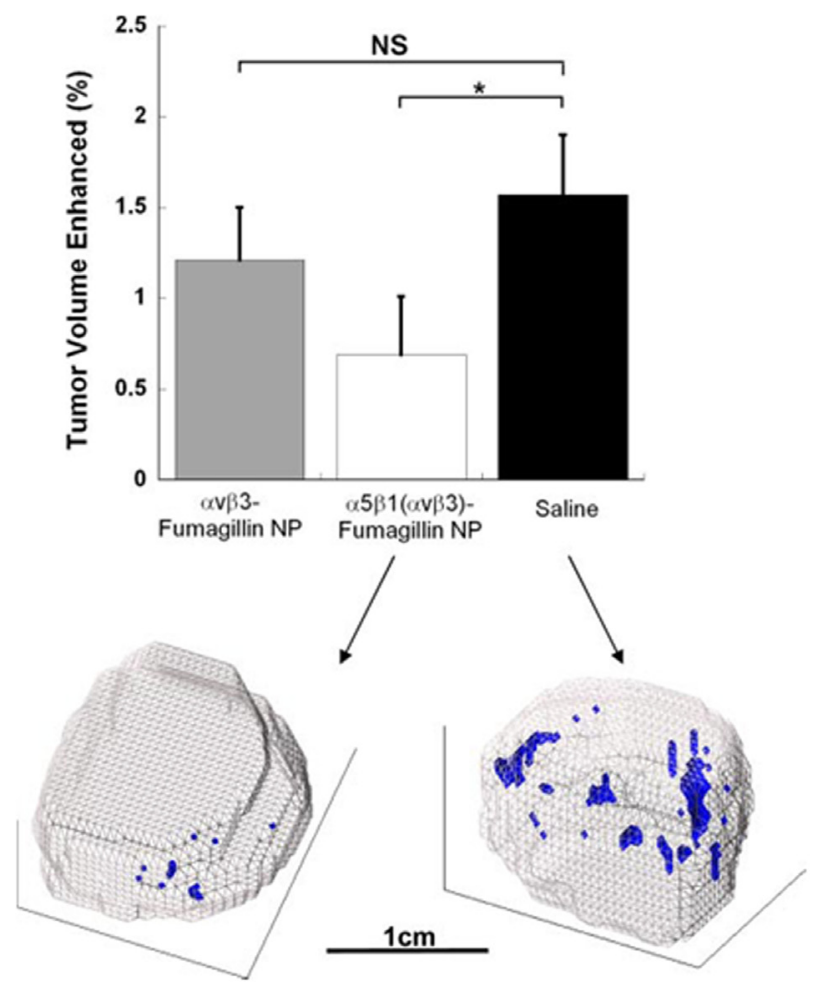

After administration of VTA which binds selectively to aminopeptidase $\mathrm{N}$, a marker for tumor neovasculature, the development of thrombosis was detected within the tumor as a reduction of tumor perfusion after USPIO administration (Fig. 8) (Persigehl et al., 2007). Furthermore, specific targeting of tumor angiogenesis markers like $\alpha_{v \beta 3}$-integrin by RGD-conjugated USPIOs showed a distinguishable uptake within tumors of different origins. This method enabled to compile a tumor specific angiogenic profile in a variety of different murine tumor models as a valuable tool for therapy monitoring (Zhang et al., 2007).

In a similar theranostic preclinical approach, lipid-based RGD paramagnetic particles were tested in order to generate a 3D map of tumor neovasculature due to MR signal enhancement (Fig. 9). Exact spatial organization of microvessels within the tumors of the control group was compared to tumors of the group after treatment with double integrin-targeted fumagillin nanoparticles directed against both; $\alpha_{5 \beta 3}$-and $\alpha_{v \beta 3}$-integrin (Schmieder et al., 2008). Tumors treated with the dual integrin-targeted particles showed significantly reduced integrin signals in their 3D maps in contrast to the control and the fumagillin nanoparticles targeted against $\alpha_{v \beta 3}$-integrin alone.

The amount of articles regarding MRI technology, the ongoing efforts in development of target specific contrast agents and technical improvements altogether allocate the growing importance of the $\mathrm{MRI}$ modality in visualization of tumor angiogenesis in preclinical and clinical studies.

\section{Future perspective and conclusion}

The fast-growing field of in vivo imaging provides a spectrum of modalities to visualize tumor angiogenesis from subcellular

Fig. 9. Magnetic resonance imaging (MRI) demonstrates the therapy response by use of targeted nanoparticles, which also have therapeutical properties. In this theranostic approach paramagnetic fumagillin nanoparticles with incorporated targeting ligands against $\alpha_{v \beta 3}$-integrin alone or against both, $\alpha_{v \beta 3}$-integrin and $\alpha_{5 \beta 1}$-integrin were applied in a melanoma xenograftmouse model. The $\alpha_{v \beta 3}$-fumagillin nanoparticles do not significantly affect the tumor vasculature, measured in the amount of signal enhancement in the tumor periphery, in comparison to saline. In contrast, treatment with the dual targeted fumagillin nanoparticles against $\alpha_{5 \beta}$-and $\alpha_{v \beta 3}$-integrin resulted in a significant reduction of tumor neovasculature as depicted in 3D maps of the tumor by MRI. Tumor is outlined in grey; contrast-enhanced pixels are blue. (The illustration is used with kind permission of FASEB Journal (Schmieder et al., 2008)). 
level up to whole body imaging. Innovative imaging techniques are emerging like Raman spectroscopy (Cai and Chen, 2007) or optoacoustic techniques, which offer anatomical and functional information by combining optical excitation with detection of acoustic signals (Wang et al., 2003).

But also, well established techniques like CT are under active development. In this respect, new blood pool contrast agents in combination with high resolution $\mu \mathrm{CT}$ s with considerably short scan times as well as tolerable $\mathrm{x}$-ray doses will be ideally suited to evaluate tumor microvessel recruitment in longitudinal studies.

Novel imaging modalities like NIRF and BLI but also for the well approved PET, SPECT and contrast enhanced MRI will particularly benefit from identification, development and evaluation of new, conclusive vessel specific biomarkers. Selective targeting of those markers will further help to monitor the efficacy of new therapeutic strategies or even can serve themselves as therapeutic tools.

Multimodal approaches like the combination of PET and CT or PET and MRI, NIRF and CT/ MRI as well as the combination of probes with "multimodal" labeling will be beneficially to combine structural, functional and molecular information of tumor progression especially concerning growth and metabolism, vascularity and metastatic spread. Since angiogenesis remains a promising target not only in anticancer treatment knowledge of angiogenic processes, evaluation of antiangiogenic therapies as well as therapy monitoring towards clinical practice are of high demand. In order to obtain vascular effects of antiangiogenic or vascular-targeting drug treatment and to provide diagnostic as well as prognostic information repeatable, well tolerable and noninvasive in vivoimaging modalities will facilitate ongoing progress in this field of research.

\section{Acknowledgements}

This work was supported by a grant from the Deutsche Forschungsgemeinschaft (AL336/5-1) within the SPP1190: The tumor-vessel-interface.

Thanks to Diana Pinkert-Leetsch for fruitful discussion.

\section{References}

ALCÁZAR J.L. (2006) Tumor angiogenesis assessed by three-dimensional power Doppler ultrasound in early, advanced and metastatic ovarian cancer:A preliminary study. Ultrasound Obstet. Gynecol. 28: 325-329.

ALMUTAIRI A., ROSSIN R., SHOKEEN M., HAGOOLY A., ANANTH A., CAPOCCIA B., GUILLAUDEU S., ABENDSCHEIN D., ANDERSON C.J., WELCH M.J., FRÉCHET J.M. (2009) Biodegradable dendritic positron-emitting nanoprobes for the noninvasive imaging of angiogenesis. Proc. Natl. Acad. Sci. USA 106:685-690.

ALVES F., DULLIN C., NAPP J., MISSBACH-GUENTNER J., JANNASCH K., MATHEJCZYK J., PARDO L.A., STÜHMER W., TIETZE L.F. (2009) Concept of a selective tumour therapy and its evaluation by near-infrared fluorescence imaging and flat-panel volume computed tomography in mice. Eur. J. Radiol. 70: 286-293.

BACKER M.V., LEVASHOVA Z., PATEL V., JEHNING B.T., CLAFFEY K., BLANKENBERG F.G., BACKER J.M. (2007) Molecular imaging of VEGF receptors in angiogenic vasculature with single-chain VEGF-based probes. Nat. Med. 13: 504-509.

BÄUERLE T., HILBIG H., BARTLING S., KIESSLING F., KERSTEN A., SCHMITTGRÄFF A., KAUCZOR H.U., DELORME S., BERGER M.R. (2008) Bevacizumab inhibits breast cancer-induced osteolysis, surrounding soft tissue metastasis, and angiogenesis in rats as visualized by VCT and MRI. Neoplasia 10: 511-520.

BEER A.J., GROSU A.L., CARLSEN J., KOLK A., SARBIA M., STANGIER I., WATZLOWIK P., WESTER H.J., HAUBNER R., SCHWAIGER M. (2007) (18F)galactoRGD positron emission tomography for imaging of alphavbeta3 expression on the neovasculature in patients with squamous cell carcinoma of the head and neck. Clin. Cancer Res. 13: 6610-6616.

BERGERS G., HANAHAN D., COUSSENS L.M. (1998) Angiogenesis and apoptosis are cellular parameters of neoplastic progression in transgenic mouse models of tumorigenesis. Int. J. Dev. Biol. 42: 995-1002.
BLANKENBERG F.G., LEVASHOVA Z., SARKAR S.K., PIZZONIA J., BACKER M.V., BACKERJ.M. (2010) Noninvasive assessment of tumor VEGF receptors in response to treatment with pazopanib: a molecular imaging study. Transl. Oncol. 3: 56-64.

BURGESS R.E., YU Y., CHRISTOFORIDIS G.A., BOUREKAS E.C., CHAKERES D.W., SPIGOS D., KANGARLU A., ABDULJALIL A.M., ROBITAILLE P.M. (1999) Human leptomeningeal and cortical vascular anatomy of the cerebral cortex at 8 Tesla. J. Comput. Assist. Tomogr. 23: 850-856.

CAI W. AND CHEN X. (2007) Nanoplatforms for targeted molecular imaging in living subjects. Small 3: 1840-1854.

CAI W., GUZMAN R., HSU A.R., WANG H., CHEN K., SUN G., GERA A., CHOI R., BLISS T., HE L., LI Z.B., MAAG A.L., HORI N., ZHAO H., MOSELEY M., STEINBERG G.K., CHEN X. (2009) Positron emission tomography imaging of poststroke angiogenesis. Stroke 40: 270-277.

CAO Y.A., WAGERS A.J., BEILHACK A., DUSICH J., BACHMANN M.H., NEGRIN R.S., WEISSMAN I.L., CONTAG C.H. (2004) Shifting foci of hematopoiesis during reconstitution from single stem cells. Proc. Natl. Acad. Sci. USA 101: 221-226.

CATANA C., WU Y., JUDENHOFER M.S., QI J., PICHLER B.J., CHERRY S.R. (2006) Simultaneous acquisition of multislice PET and MR images: initial results with a MR-compatible PET scanner. J. Nucl. Med. 47: 1968-1976.

CEELEN W., SMEETS P., BACKES W., VAN DAMME N., BOTERBERG T., DEMETTER P., BOUCKENOOGHE I., DE VISSCHERE M., PEETERS M., PATTYN P. (2006) Noninvasive monitoring of radiotherapy-induced microvascular changes using dynamic contrast enhanced magnetic resonance imaging (DCE-MRI) in a colorectal tumor model. Int. J. Radiat. Oncol. Biol. Phys. 64: 1188-1196.

CHEN K., CAI W., LI Z.B., WANG H., CHEN X. (2009) Quantitative PET imaging of VEGF receptor expression. Mol. Imaging Biol. 11: 15-22.

CHEN X., HOU Y., TOHME M., PARK R., KHANKALDYYAN V., GONZALES-GOMEZ I., BADING J.R., LAUG W.E., CONTI P.S. (2004) Pegylated Arg-Gly-Asp peptide: 64Cu labeling and PET imaging of brain tumor alphavbeta3-integrin expression. J. Nucl. Med. 45: 1776-1783.

CHEN X. (2006) Multimodality imaging of tumor integrin alphavbeta3 expression. Mini Rev. Med. Chem. 6: 227-234.

CHUNG S., SUDO R., VICKERMAN V., ZERVANTONAKIS I.K., KAMM R.D. (2010) Microfluidic platforms for studies of angiogenesis, cell migration, and cell-cell interactions. Sixth International Bio-Fluid Mechanics Symposium and Workshop March 28-30, 2008 Pasadena, California. Ann. Biomed. Eng. 38: 1164-1177.

CHRISTOFORIDIS G.A., YANG M., KONTZIALIS M.S., LARSON D.G., ABDULJALIL A., BASSO M., YANG W., RAY-CHAUDHURYA., HEVERHAGEN J., KNOPP M.V., BARTH R.F. (2009) High resolution ultra high field magnetic resonance imaging of glioma microvascularity and hypoxia using ultra-small particles of iron oxide. Invest. Radiol. 44: 375-383.

DASHNER R.A., KANGARLU A., CLARK D.L., RAYCHAUDHURY A., CHAKERES D.W. (2004) Limits of 8-Tesla magnetic resonance imaging spatial resolution of the deoxygenated cerebral microvasculature. J. Magn. Reson. Imaging 19: 303-307.

DULLIN C., ZIENTKOWSKA M., NAPP J., MISSBACH-GUENTNER J., KRELL H.W., MÜLLER F., GRABBE E., TIETZE L.F., ALVES F. (2009) Semiautomatic landmarkbased two-dimensional-three-dimensional image fusion in living mice: correlation of near-infrared fluorescence imaging of Cy5.5-labeled antibodies with flat-panel volume computed tomography. Mol. Imaging 8: 2-14.

ECCLES S.A. (2004) Parallels in invasion and angiogenesis provide pivotal points for therapeutic intervention. Int. J. Dev. Biol. 48: 583-598.

EREMINA V., JEFFERSON J.A., KOWALEWSKA J., HOCHSTER H., HAAS M., WEISSTUCH J., RICHARDSON C., KOPP J.B., KABIR M.G., BACKX P.H. et al (2008) VEGF inhibition and renal thrombotic microangiopathy. N. Engl. J. Med. 358: 1129-1136.

FOLKMAN J. (1992) The role of angiogenesis in tumor growth. Semin Cancer Biol. 3: $65-71$.

FORD N.L., THORNTON M.M., HOLDSWORTHD.W. (2003) Fundamental image quality limits for microcomputed tomography in small animals. Med. Phys. 30: 2869-2877.

FRANCB.L., ACTONP.D., MARIC., HASEGAWAB.H. (2008) Small-animal SPECT and SPECT/CT: important tools for preclinical investigation. J. Nucl. Med. 49:1651-1663.

GAMBHIRS.S. (2002) Molecular imaging of cancer with positron emission tomography. Nat. Rev. Cancer 2: 683-693.

GILES F.J., BELLAMY W.T., ESTROV Z., O'BRIEN S.M., VERSTOVSEK S., RAVANDI F., BERAN M., BYCOTT P., PITHAVALA Y., STEINFELDT H., et al (2006) The anti-angiogenesis agent, AG-013736, has minimal activity in elderly patients 
with poor prognosis acute myeloid leukemia (AML) or myelodysplastic syndrome (MDS). Leuk. Res. 30: 801-811.

GOORDEN M.C. AND BEEKMAN F.J. (2010) High-resolution tomography of positron emitters with clustered pinhole SPECT. Phys. Med. Biol. 55: 1265-1277.

GRABHERR S., HESS A., KAROLCZAK M., THALI M.J., FRIESS S.D., KALENDER W.A., DIRNHOFER R., DJONOV V. (2008) Angiofil-mediated visualization of the vascular system by microcomputed tomography: a feasibility study. Microsc. Res. Tech. 71: 551-556.

GRESCHUS S., KIESSLING F., LICHY M.P., MOLL J., MUELLER M.M., SAVAI R., ROSE F., RUPPERT C., GÜNTHER A., LUECKE M., FUSENIG N.E., SEMMLER W., TRAUPE H. (2005) Potential applications of flat-panel volumetric CT in morphologic and functional small animal imaging. Neoplasia 7: 730-740.

GRIFFIOEN A.W., VAN DER SCHAFT D.W., BARENDSZ-JANSON A.F., COX A. STRUIJKERBOUDIER H.A., HILLEN H.F., MAYOK.H. (2001)Anginex, a designed peptide that inhibits angiogenesis. Biochem J. 354: 233-242.

HARTNETT L., GLYNN C., NOLAN C.M., GREALY M., BYRNES L. (2010) Insulin-like growth factor-2 regulates early neural and cardiovascular system development in zebrafish embryos. Int. J. Dev. Biol. 54: 573-583.

HOFFMAN R.M. (2009) Imaging cancer dynamics in vivo at the tumor and cellular level with fluorescent proteins. Clin. Exp. Metastasis 26: 345-355.

HSU A.R., HOU L.C., VEERAVAGU A., GREVE J.M., VOGEL H., TSE V., CHEN X. (2006) In vivo near-infrared fluorescence imaging of integrin alphavbeta3 in an orthotopic glioblastoma model. Mol. Imaging Biol 8: 315-323.

IDÉE J.M., PORT M., ROBERT P., RAYNAL I., PRIGENT P., DENCAUSSE A., LE GRENEUR S., TICHKOWSKY I., LE LEM G., BOURRINET P. et al (2001) Preclinical profile of the monodisperse iodinated macromolecular blood pool agent P743. Invest. Radiol. 36: 41-49.

IZZEDINE H., RIXE O., BILLEMONT B., BAUMELOU A., DERAY G. (2007) Angiogenesis inhibitor therapies: focus on kidney toxicity and hypertension. Am. J. Kidney. Dis. 50: 203-218.

JAIN R.K. (2001) Normalizing tumor vasculature with anti-angiogenic therapy: a new paradigm for combination therapy. Nat. Med. 7: 987-989.

JANNASCH K., DULLIN C., HEINLEIN C., KREPULAT F., WEGWITZ F., DEPPERT W., ALVES F. (2009) Detection of different tumor growth kinetics in single transgenic mice with oncogene-induced mammary carcinomas by flat-panel volume computed tomography. Int. J. Cancer 125: 62-70.

JENKINS D.E., OEI Y., HORNIG Y.S., YU S.F., DUSICH J., PURCHIO T., CONTAG P.R. (2003) Bioluminescent imaging (BLI) to improve and refine traditional murine models of tumor growth and metastasis. Clin. Exp. Metastasis 20: 733-744

JONES T. (1996) The role of positron emission tomography within the spectrum of medical imaging. Eur. J. Nucl. Med. 23: 207-211.

KALENDER W.A. (2003) The use of flat-panel detectors for CT imaging. Radiologe 43: 379-387.

KALENDER W.A. AND KYRIAKOU Y. (2007) Flat-detector computed tomography (FD-CT). Eur. Radiol. 17: 2767-2779.

KAO C.Y., HOFFMAN E.A., BECK K.C., BELLAMKONDA R.V., ANNAPRAGADAA.V. (2003) Long-residence-time nano-scale liposomal iohexol for X-ray-based blood pool imaging. Acad. Radiol. 10: 475-483.

KIENAST Y., VON BAUMGARTEN L., FUHRMANN M., KLINKERT W.E., GOLDBRUNNER R., HERMS J., WINKLER F. (2010) Real-time imaging reveals the single steps of brain metastasis formation. Nat. Med. 16: 116-122.

KIESSLING F., GRESCHUSS., LICHYM.P., BOCKM., FINKC., VOSSELERS., MOLL J., MUELLERM.M., FUSENIG N.E., TRAUPE H., SEMMLERW. (2004) Volumetric computed tomography (VCT): a new technology for noninvasive, high-resolution monitoring of tumor angiogenesis. Nat. Med. 10: 1133-1138.

KIESSLING F., HUPPERT J., PALMOWSKI M. (2009) Functional and molecular ultrasound imaging: Concepts and contrast agents. Curr. Med. Chem. 16: 627-642.

KIM K.J., LI B., WINER J., ARMANINI M., GILLETT N., PHILLIPS H.S., FERRARA N. (1993) Inhibition of vascular endothelial growth factor-induced angiogenesis suppresses tumour growth in vivo. Nature 362: 841-844.

KISELEV V.G., STRECKER R., ZIYEH S., SPECK O., HENNIG J. (2005) Vessel size imaging in humans. Magn. Reson. Med. 53: 553-563.

KLIBANOV A.L. (2006) Microbubble contrast agents: targeted ultrasound imaging and ultrasound-assisted drug-delivery applications. Invest. Radiol. 41: 354- 362.
KOBAYASHI H., REIJNDERS K., ENGLISH S., YORDANOV A.T., MILENIC D.E., SOWERS A.L., CITRIN D., KRISHNA M.C., WALDMANN T.A., MITCHELL J.B., BRECHBIEL M.W. (2004) Application of a macromolecular contrast agent for detection of alterations of tumor vessel permeability induced by radiation. Clin. Cancer Res. 10: 7712-7720.

KOBAYASHI N., ALLEN N., CLENDENON N.R., KO L.W. (1980) An improved rat brain-tumor model. J. Neurosurg. 53: 808-815.

KOEHL G.E., GAUMANN A., GEISSLER E.K. (2009) Intravital microscopy of tumor angiogenesis and regression in the dorsal skin fold chamber: mechanistic insights and preclinical testing of therapeutic strategies. Clin Exp Metastasis 26: 329-344.

KOSSODO S., PICKARSKI M., LIN S.A., GLEASON A., GASPAR R., BUONO C., HO G., BLUSZTAJN A., CUNEO G., ZHANG J. et al (2009) Dual in vivo quantification of integrin-targeted and protease-activated agents in cancer using fluorescence molecular tomography (FMT). Mol. Imaging Biol. 12: 488-499.

LEVASHOVA Z., BACKER M., BACKER J.M., BLANKENBERG F.G. (2008) Direct site-specific labeling of the Cys-tag moiety in scVEGF with technetium 99m. Bioconjug. Chem. 19: 1049-1054.

LIY., GONZALEZS., TERWEYT.H., WOLCHOKJ., LIY., ARANDAI., TOLEDO-CROW R., HALPERN A.C. (2009) Dual mode reflectance and fluorescence confocal laser scanning microscopy for in vivo imaging melanoma progression in murine skin. J. Invest. Dermatol. 125: 798-804.

LIJOWSKI M., CARUTHERS S., HU G., ZHANG H., SCOTT M.J., WILLIAMS T., ERPELDING T., SCHMIEDER A.H., KIEFER G., GULYAS G., ATHEY P.S., GAFFNEY P.J., WICKLINE S.A., LANZA G.M. (2009) High sensitivity: high-resolution SPECT-CT/MR molecular imaging of angiogenesis in the $\mathrm{V} \times 2$ model. Invest. Radiol. 44: 15-22.

LIN K.Y., MARICEVICH M., BARDEESY N., WEISSLEDER R., MAHMOOD U. (2008) In vivo quantitative microvasculature phenotype imaging of healthy and malignant tissues using a fiber-optic confocal laser microprobe. Transl. Oncol. 1: 84-94.

LINDNER J.R. (2004) Molecular imaging with contrast ultrasound and targeted microbubbles. J. Nucl. Cardiol. 11: 215-221.

MAEHARA N. (2008) Experimental microcomputed tomography study of the 3D microangioarchitecture of tumors. Eur. Radiol. 13: 1559-1565.

MASSOUD T.F., GAMBHIR S.S. (2003) Molecular imaging in living subjects: seeing fundamental biological processes in a new light. Genes Dev. 17: 545-580.

MATSUMOTO S., YASUI H., BATRA S., KINOSHITA Y., BERNARDO M., MUNASINGHE J.P., UTSUMI H., CHOUDHURI R., DEVASAHAYAM N., SUBRAMANIAN S., MITCHELL J.B., KRISHNA M.C. (2009) Simultaneous imaging of tumor oxygenation and microvascular permeability using Overhauser enhanced MRI. Proc. Natl. Acad. Sci. USA 106: 17898-17903.

MCELROY W.D. (1951) Properties of the reaction utilizing adenosinetriphosphate for bioluminescence. J. Biol. Chem. 191: 547-557.

MCINTYRE J.O., MATRISIAN L.M. (2003) Molecular imaging of proteolytic activity in cancer. J. Cell Biochem. 90: 1087-1097.

MISSBACH-GUENTNER J., DULLIN C., ZIENTKOWSKAM., DOMEYER-MISSBACH M., KIMMINAS., OBENAUER S., KAUER F., STÜHMER W., GRABBE E., VOGEL W.F., ALVES F. (2007) Flat-panel detector-based volume computed tomography: a novel 3D imaging technique to monitor osteolytic bone lesions in a mouse tumor metastasis model. Neoplasia 9: 755-765.

MISSBACH-GUENTNER J., DULLINC., KIMMINAS., ZIENTKOWSKAM., DOMEYERMISSBACHM., MALZC., GRABBE E., STÜHMERW., ALVESF. (2008) Morphologic changes of mammary carcinomas in mice over time as monitored by flat-pane detector volume computed tomography. Neoplasia 10: 663-673.

MONTET X., FIGUEIREDO J.L., ALENCAR H., NTZIACHRISTOS V., MAHMOOD U. WEISSLEDER R. (2007) Tomographic fluorescence imaging of tumor vascular volume in mice. Radiology 242: 751-758.

MOROZ E., CARLIN S., DYOMINA K., BURKE S., THALER H.T., BLASBERG R., SERGANOVA I. (2009) Real-time imaging of HIF-1alpha stabilization and degradation. PLoS One 4: e5077.

MULDERW.J., VANDERSCHAFT D.W., HAUTVASTP.A., STRIJKERSG.J., KONING G.A., STORM G., MAYO K.H., GRIFFIOEN A.W., NICOLAY K. (2007) Early in vivo assessment of angiostatic therapy efficacy by molecular MRI. FASEBJ.21:378-383.

NGUYEN HUU S., OSTER M., UZAN S., CHAREYRE F., ARACTINGI S., KHOSROTEHRANIK. (2007) Maternal neoangiogenesis during pregnancy partly derives from fetal endothelial progenitor cells. Proc. Natl. Acad. Sci. USA 104: 1871-1876. NILSSON F., KOSMEHL H., ZARDI L., NERI D. (2001) Targeted delivery of tissue 
factor to the ED-B domain of fibronectin, a marker of angiogenesis, mediates the infarction of solid tumors in mice. Cancer Res. 61: 711-716.

NTZIACHRISTOS V., TUNG C.H., BREMERC., WEISSLEDERR. (2002) Fluorescence molecular tomography resolves protease activity in vivo. Nat. Med. 8: 757-760.

O'REILLY M.S., BOEHM T., SHING Y., FUKAI N., VASIOS G., LANE W.S., FLYNN E., BIRKHEAD J.R., OLSEN B.R., FOLKMAN J. (1997) Endostatin: an endogenous inhibitor of angiogenesis and tumor growth. Cell 88: 277-285.

PADHANI A.R. AND NEEMAN M. (2001) Challenges for imaging angiogenesis. Br. J. Radiol. 74: 886-890.

PALMOWSKI M., HUPPERT J., HAUFF P., REINHARDT M., SCHREINER K., SOCHERM.A., HALLSCHEIDTP., KAUFFMANNG.W., SEMMLERW., KIESSLING F. (2008) Vessel fractions in tumor xenografts depicted by flow- or contrast-sensitive three-dimensional high-frequency Doppler ultrasound respond differently to antiangiogenic treatment. Cancer Res. 68: 7042-7049.

PALMOWSKI M., PESCHKE P., HUPPERT J., HAUFF P., REINHARDT M., MAURER M., KARGER C.P., SCHOLZ M., SEMMLER W., HUBER P.E., KIESSLING F.M. (2009) Molecular ultrasound imaging of early vascular response in prostate tumors irradiated with carbon ions. Neoplasia 11: 856-863.

PERSIGEHL T., BIEKER R., MATUSZEWSKI L., WALL A., KESSLER T., KOOIJMAN H., MEIER N., EBERT W., BERDEL W.E., HEINDEL W., MESTERS R.M., BREMER C. (2007) Antiangiogenic tumor treatment: early noninvasive monitoring with USPIO-enhanced MR imaging in mice. Radiology 244: 449-456.

PHELPS M.E. (2000) PET: the merging of biology and imaging into molecular imaging. J. Nucl. Med. 41: 661-681.

PILLAIR., MARINELLIE.R., FANH., NANJAPPANP., SONG B., VON WRONSKI M.A., CHERKAOUIS., TARDYI., POCHONS., SCHNEIDERM., NUNNA.D., SWENSON R.E. (2010) A phospholipid-PEG2000 conjugate of a vascular endothelial growth factor receptor 2 (VEGFR2)-targeting heterodimer peptide for contrast-enhanced ultrasound imaging of angiogenesis. Bioconjug. Chem. 21: 556-562.

PIYAWATTANAMETHA W., COCKER E.D., BURNS L.D., BARRETTO R.P., JUNG J.C., RA H., SOLGAARD O., SCHNITZER M.J. (2009) In vivo brain imaging using a portable $2.9 \mathrm{~g}$ two-photon microscope based on a microelectromechanical systems scanning mirror. Opt. Lett. 34: 2309-2311.

PUDLISZEWSKIM. AND PARDANAUD L. (2005) Vasculogenesis and angiogenesis in the mouse embryo studied using quail/mouse chimeras. Int. J. Dev. Biol. 49:355-361.

REHEMTULLA A., STEGMAN L.D., CARDOZO S.J., GUPTAS., HALLD.E., CONTAG C.H., ROSS B.D. (2000) Rapid and quantitative assessment of cancer treatment response using in vivo bioluminescence imaging. Neoplasia 2: 491-495.

RIBATTI D., VACCA A., RONCALI L., DAMMACCO F. (1996) The chick embryo chorioallantoic membrane as a model for in vivo research on angiogenesis. Int. J. Dev. Biol. 40: 1189-1197.

RUOSLAHTIE. (2002) Specialization of tumourvasculature. Nat. Rev. Cancer2: 83-90.

SAVAI R., LANGHEINRICH A.C., SCHERMULY R.T., PULLAMSETTI S.S., DUMITRASCU R., TRAUPE H., RAU W.S., SEEGER W., GRIMMINGER F., BANAT G.A. (2009) Evaluation of angiogenesis using micro-computed tomography in a xenograft mouse model of lung cancer. Neoplasia 11: 48-56.

SCHMIEDER A.H., CARUTHERS S.D., ZHANG H., WILLIAMS T.A., ROBERTSON J.D., WICKLINE S.A., LANZA G.M. (2008) Three-dimensional MR mapping of angiogenesis with alpha5beta1 (alpha nu beta3)-targeted theranostic nanoparticles in the MDA-MB-435 xenograft mouse model. FASEB J. 22: 4179-4189.

SEDELAAR J.P., VAN LEENDERS G.J., HULSBERGEN-VAN DE KAA C.A., VAN DER POEL H.G., VAN DER LAAK J.A., DEBRUYNE F.M., WIJKSTRA H., DE LA ROSETTE J.J. (2001) Microvessel density: correlation between contrast ultrasonography and histology of prostate cancer. Eur. Urol. 40: 285-293.

SESHADRI M. AND CIESIELSKI M.J. (2009) MRI-based characterization of vascular disruption by 5,6-dimethylxanthenone-acetic acid in gliomas. J. Cereb. Blood Flow Metab. 29: 1373-1382.

SEVICK-MURACA E.M., HOUSTON J.P., GURFINKEL M. (2002) Fluorescenceenhanced, near infrared diagnostic imaging with contrast agents. Curr. Opin. Chem. Biol. 6:642-650.

SHOKEEN M. AND ANDERSON C.J. (2009) Molecular imaging of cancer with copper-64 radiopharmaceuticals and positron emission tomography (PET). Acc. Chem. Res. 42: 832-841.

SMITH L.A., TIFFIN N., THOMSON M., CROSS S.S., HURLSTONE D.P. (2008) Chromoscopic endomicroscopy: in vivo cellular resolution imaging of the colorectum. J. Gastroenterol. Hepatol. 23: 1009-1023.
SPANOUDAKI V.C. AND ZIEGLER S.I. (2008) PET \& SPECT instrumentation. Handb. Exp. Pharmacol. 185: 53-74.

STONE R.L., SOOD A.K., COLEMAN R.L. (2010) Collateral damage: toxic effects of targeted antiangiogenic therapies in ovarian cancer. Lancet Oncol. 11: 465-475.

TOMBACH B., REIMER P., BREMER C., ALLKEMPER T., ENGELHARDT M. MAHLER M., EBERT W., HEINDEL W. (2004) First-pass and equilibrium-MRA of the aortoiliac region with a superparamagnetic iron oxide blood pool MR contrast agent (SH U $555 \mathrm{C}$ ): results of a human pilot study. NMR Biomed. 17: 500-506.

TOWNSEND D.W. AND BEYER T. (2002) A combined PET/CT scanner: the path to true image fusion. Br. J. Radiol. 75: 24-30.

TOZER G.M., KANTHOU C., BAGULEYB.C. (2005) Disrupting tumour blood vessels. Nat. Rev. Cancer 5: 423-435.

TROPRÈS I., LAMALLE L., PÉOC'H M., FARION R., USSON Y., DÉCORPS M. RÉMY C. (2004) In vivo assessment of tumoral angiogenesis. Magn. Reson. Med. 51: 533-541.

TSENG J., DUNNWALD L.K., SCHUBERT E.K., LINK J.M., MINOSHIMA S., MUZI M., MANKOFF D.A. (2004) 18F-FDG kinetics in locally advanced breast cancer: correlation with tumor blood flow and changes in response to neoadjuvant chemotherapy. J. Nucl. Med. 45: 1829-1837.

TSIEN R.Y. (2005) Building and breeding molecules to spy on cells and tumors. FEBS Lett. 579: 927-932.

VAUPEL P., KALLINOWSKI F., OKUNIEFF P. (1989) Blood flow, oxygen and nutrient supply, and metabolic microenvironment of human tumors: a review. Cancer Res. 49: 6449-6465.

WAHL R.L., HUTCHINS G.D., BUCHSBAUM D.J., LIEBERT M., GROSSMAN H.B., FISHER S. (1991) 18F-2-deoxy-2-fluoro-D-glucose uptake into human tumor xenografts. Feasibility studies for cancer imaging with positron-emission tomography. Cancer 67: 1544-1550.

WANG X., PANG Y., KU G., XIE X., STOICA G., WANG L.V. (2003) Noninvasive laserinduced photoacoustic tomography for structural and functional in vivo imaging of the brain. Nat. Biotechnol. 21: 803-806.

WEICHERT J.P., LEE F.T., CHOSY S.G., LONGINO M.A., KUHLMAN J.E., HEISEY D.M., LEVERSON G.E. (2000) Combined hepatocyte-selective and blood-pool contrast agents for the CT detection of experimental liver tumors in rabbits. Radiology 216: 856-871.

WEISSLEDER R., ELIZONDO G., WITTENBERG J., RABITO C.A., BENGELE H.H JOSEPHSON L. (1990) Ultrasmall superparamagnetic iron oxide: characterization of a new class of contrast agents for MR imaging. Radiology 175: 489-493.

WEISSLEDER R., TUNG C.H., MAHMOOD U., BOGDANOV A. JR. (1999) In vivo imaging of tumors with protease-activated near-infrared fluorescent probes. Nat. Biotechnol. 17: 375-378.

WEISSLEDER R. AND PITTET M.J. (2008) Imaging in the era of molecular oncology. Nature 452: 580-589.

WILSON C.B., LAMMERTSMA A.A., MCKENZIE C.G., SIKORA K., JONES T. (1992) Measurements of blood flow and exchanging water space in breast tumors using positron emission tomography: a rapid and noninvasive dynamic method. Cancer Res. 52: 1592-1597.

WINKLER F., KIENAST Y., FUHRMANN M., VON BAUMGARTEN L., BURGOLD S. MITTEREGGER G., KRETZSCHMAR H., HERMS J. (2009) Imaging glioma cell invasion in vivo reveals mechanisms of dissemination and peritumoral angiogenesis. Glia 57: 1306-1315.

YANG M., LI L., JIANG P., MOOSSAA.R., PENMAN S., HOFFMAN R.M. (2003) Dualcolor fluorescence imaging distinguishes tumor cells from induced host angiogenic vessels and stromal cells. Proc. Natl. Acad. Sci. USA 100: 14259-14262.

YANG W.T., TSE G.M., LAM P.K., METREWELI C., CHANG J. (2002) Correlation between color power Doppler sonographic measurement of breast tumor vasculature and immunohistochemical analysis of microvessel density for the quantitation of angiogenesis. J. Ultrasound Med. 21: 1227- 1235.

ZAKARIJA A. AND SOFF G. (2005) Update on angiogenesis inhibitors. Curr. Opin. Oncol. 17: 578-583.

ZETTERB.R. (1998) Angiogenesis and tumor metastasis. Annu Rev. Med. 49:407-424

ZHANG C., JUGOLD M., WOENNE E.C., LAMMERST., MORGENSTERN B., MUELLER M.M., ZENTGRAF H., BOCK M., EISENHUTM., SEMMLER W., KIESSLING F. (2007) Specific targeting of tumor angiogenesis by RGD-conjugated ultrasmall superparamagnetic iron oxide particles using a clinical 1.5-T magnetic resonance scanner. Cancer Res 67: 1555-1562. 


\section{Further Related Reading, published previously in the Int. J. Dev. Biol.}

Insulin-like growth factor-2 regulates early neural and cardiovascular system development in zebrafish embryos Lori Hartnett, Catherine Glynn, Catherine M. Nolan, Maura Grealy and Lucy Byrnes Int. J. Dev. Biol. (2010) 54: 573-583

The seminal work of Werner Risau in the study of the development of the vascular system Domenico Ribatti

Int. J. Dev. Biol. (2010) 54: 567-572

Estrogen regulation of placental angiogenesis and fetal ovarian development during primate pregnancy Eugene D. Albrecht and Gerald J. Pepe Int. J. Dev. Biol. (2010) 54: 397-407

Uteroplacental vascular development and placental function: an update Lawrence P. Reynolds, Pawel P. Borowicz, Joel S. Caton, Kimberly A. Vonnahme, Justin S. Luther, David S. Buchanan, Shireen A. Hafez, Anna T. Grazul-Bilska and Dale A. Redmer Int. J. Dev. Biol. (2010) 54: 355-365

Critical growth factors and signalling pathways controlling human trophoblast invasion Martin Knöfler Int. J. Dev. Biol. (2010) 54: 269-280

Over-expression of thymosin beta4 promotes abnormal tooth development and stimulation of hair growth Hee-Jae Cha, Deborah Philp, Soo-Hyun Lee, Hye-Sung Moon, Hynda K. Kleinman and Takashi Nakamura Int. J. Dev. Biol. (2010) 54: 135-140

The contribution of Roberto Montesano to the study of interactions between epithelial sheets and the surrounding extracellular matrix Domenico Ribatti

Int. J. Dev. Biol. (2010) 54: 1-6

A critical role for myoglobin in zebrafish development Danielle H. Vlecken, Janwillem Testerink, Elisabeth B. Ott, Philippe A. Sakalis, Richard T. Jaspers and Christoph P. Bagowski Int. J. Dev. Biol. (2009) 53: 517-524

Embryonic development of the proepicardium and coronary vessels Anna Ratajska, Elzbieta Czarnowska and Bogdan Ciszek Int. J. Dev. Biol. (2008) 52: 229-236

Vasculogenesis and angiogenesis in the mouse embryo studied using quail/mouse chimeras Michel Pudliszewski and Luc Pardanaud Int. J. Dev. Biol. (2005) 49: 355-361

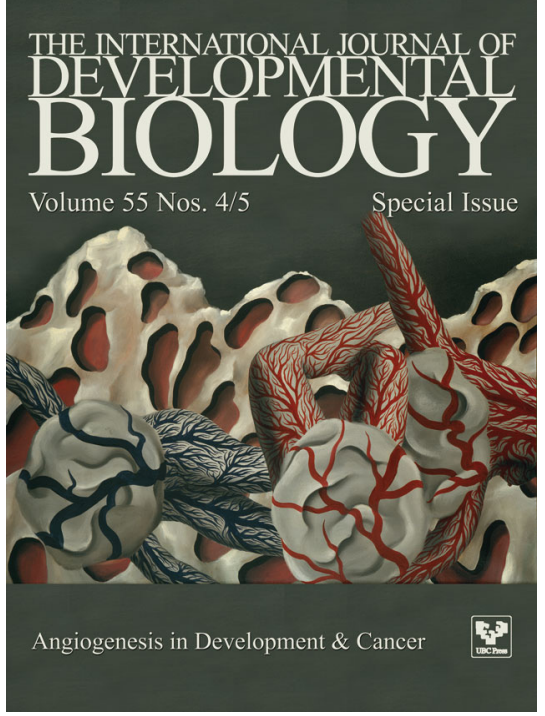

Impact Factor $(\mathbf{2 0 1 0})=\mathbf{2 . 8 6}$

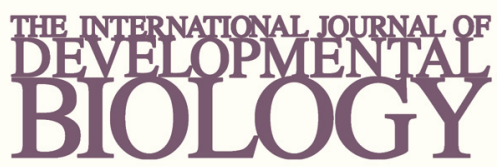

Volume 54 Nos. 6/7
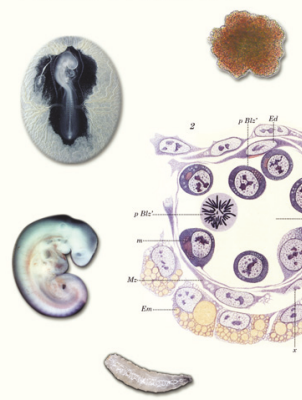

Special Issue
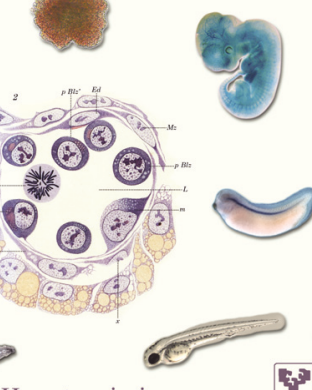

Developmental Hematopoiesis

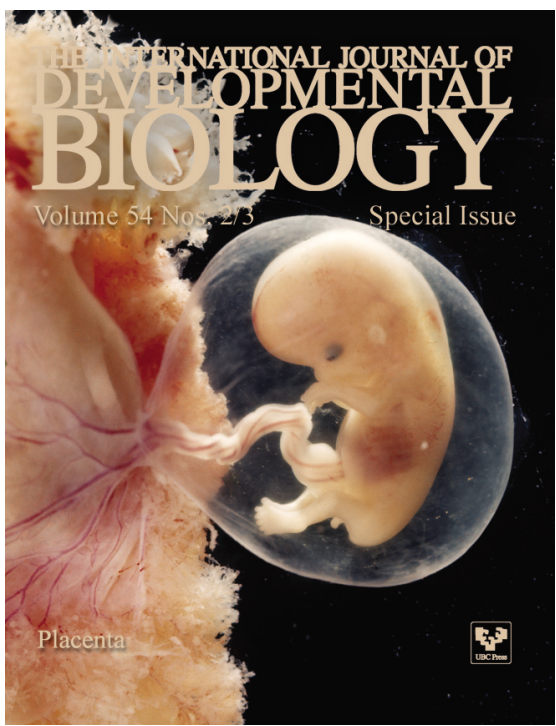

